\title{
Application of Box-Behnken design and desirability function in the development and optimization of self-nanoemulsifying drug delivery system for enhanced dissolution of ezetimibe
}

\author{
Pragya Yadav ${ }^{*}$, Vaibhav Rastogi and Anurag Verma
}

\begin{abstract}
Background: This study is focused on developing and optimizing a self-nanoemulsifying drug delivery system (SNEDDS) of BCS class II drug (ezetimibe) through Box-Behnken design (BBD) and desirability function for enhanced dissolution.

Pseudoternary phase diagrams were created by taking oil (Peceol), surfactant (Tween80), and co-surfactant (Transcutol-P) and the concentration ranges were identified for generating BBD. The composition of ezetimibeSNEDDS was optimized through various response variables viz. globule size $\left(Y_{1}\right)$, \%transmittance $\left(Y_{2}\right)$, selfemulsification time $\left(Y_{3}\right)$, dissolution after $5 \mathrm{~min}$ and $40 \mathrm{~min}\left(Y_{4}, Y_{5}\right)$. Optimized formulation was characterized for various physicochemical properties.

Results: Pseudoternary phase diagram having maximum nano-emulsification area was selected to formulate SNEDDS. Derived polynomial equation and model graphs were exercised to investigate the impact of formulation variables on the responses. Significant effect of formulation composition on the responses was observed $(p<0.05)$. The formulation with least oil (10\%) and high surfactant (60\%) exhibited low globule size (24.4 $\pm 2.07 \mathrm{~nm})$, low emulsification time (55 s) but high \%transmittance (101.2\%) and drug release (49.21\% after 5 min; $95.27 \%$ after $40 \mathrm{~min}$ ). Based on the desirability function, the optimized formulation was selected and reformulated. The optimized formulation (FF1) was found to be uniform, stable, and showed similar observed and predicted responses.

Conclusion: The potential of SNEDDS in improving the dissolution profile of weakly soluble drug and the applicability of BBD with desirability function in optimizing a SNEDD formulation has made it possible to identify the impact of various independent variables on optimization of the formulation for better responses.
\end{abstract}

Keywords: SNEDDS, BCS, Box-Behnken design, Ezetimibe, Desirability function, Optimization

\footnotetext{
* Correspondence: ingenious.pragya@gmail.com

Department of Pharmaceutics, Faculty of Pharmacy, IFTM University,

Moradabad, (U.P.) 244102, India
} 


\section{Background}

Administering drugs by means of oral route is considered ideal for a variety of drugs and hence, $80 \%$ of the available dosage forms are being administered orally. Moreover, oral administration of drug is also preferred for various kinds of dosage forms (controlled release, sustained release, fast release dosage forms, etc.) with a far different preparation methodology. However, it is the physicochemical property of the drug which needs to be explored and assessed for selecting an ideal route of administration. For example, very low aqueous solubility of the majority of drugs ( $68 \%$ of oral drugs have poor solubility, $<100 \mu \mathrm{g} / \mathrm{mL}$ ) lead to inadequate dissolution in the gastric milieu after oral administration which eventually show low bioavailability and thus suboptimal efficacy $[1,2]$.

These drugs are classified as class II drugs by the Biopharmaceutical Classification System, drugs with poor aqueous solubility and high permeability [3]. If the oral administration route is constrained for giving drugs having irrational property then the solution lies in developing a tailored dosage forms. Therefore, a lot of emphasis has been given by the scientists and researchers in recent years, on improving the solubility of such scantily watersoluble drugs either by using formulation strategies like crystal engineering [4], solid dispersion [5], cyclodextrin complexation [6], micronization, and nanosization [7], or chemical strategies such as salt formation [8], prodrugs [9], and lipidic systems [10] including SNEDDS which is considered to be one of the prospective nanotechnologybased drug delivery approach used to optimize the dissolution time and hence bioavailability of low soluble drugs.

SNEDDS are lipid-based formulations and are basically the blend of oils from the natural or synthetic origin and surfactants, or it can be a mixture of hydrophilic solvents and cosolvents/surfactants used for improving the solubility of lipophilic drugs $(\log P>3)$ [14]. On oral ingestion, the preconcentrate of SNEDDS transform into oil-in-water type emulsion having fine globules of size ranges to micron (microemulsion) or nano (nanoemulsion). The transformation of SNEDDS preconcentrate into fine globules takes place due to mild agitation (in vitro) or digestive motility (in vivo) in the presence of simulated fluid or Gastric fluid (in vivo) and thus it is considered to be an important phenomenon for self-emulsification [11].

Formation of stable formulation that can be filled into capsules, high entrapment efficiency for drug, spontaneous formation of emulsion which aid in bypassing the dissolution step and preventing degradation of the drug in gastric media are some common advantages linked with SNEDDS. In addition, the spontaneous emulsification of SNEDDS preconcentrate results in the formation of micro/nanosized globule which will provide a large surface area for absorption thereby, enhancing the rate and magnitude of absorption that will ultimately result in improved bioavailability [12]. On oral administration, lipase enzymes (lingual and pancreatic) act on the lipid/oily phase of the SNEDDS and form emulsified glycerides and fatty acids. Thereafter, intestinal mixed micelles are formed from glycerides and fatty acids in the presence of bile acids. These mixed micelles then passed through intestinal cell (enterocytes) and form chylomicrons. These formed chylomicrons, containing drug, facilitate lymphatic transport thus bypassing the liver (first-pass effect) and thereby enhance the bioavailability of lipophilic drugs [13].

Selection of excipients for the formulation of potent, stable SNEDDS is very critical and thus requires a comprehensive knowledge of the oil phase, surfactants, and co-surfactants used to prepare SNEDDS. Physicochemical properties of lipid or oil phase (e.g., polarity, viscosity and molecular volume) considerably preside the spontaneity of the nano-emulsification, globule size, solubility of drug, and biological fate of the nanoemulsions and the entrapped drug [14]. The surfactant which possesses highsolubilization capacity for the drug and have the ability to lower the interfacial tension at the water and oil interface should be selected for the formulation of SNEDDS.

The high HLB (HLB > 12) and thus surfactant's hydrophilicity is a prerequisite for the instantaneous development of oil droplets in water and/or fast distribution of the formulation in the gastric milieu or aqueous environment, ensuring an excellent self-emulsifying/dispersing performance [15]. However, it is difficult for a single surfactant to produce transient negative interfacial tension which necessitates the inclusion of a cosurfactant [15].

Co-surfactant helps in building a fluid interfacial film which affects the interfacial bending stress by reducing it and thus cater an ample flexibility to the interfacial film for obtaining different curvatures obligatory to form nanoemulsions over a broad array of composition $[12,16]$. Hence, the scalability of SNEDDS is dependent on the optimized selection of its components.

In the present investigation, Box-Behnken design (BBD) along with desirability function was used to design and optimize SNEDDS formulation containing a BCS class II model drug, ezetimibe (EZT, water solubility $=0.00846$ $\mathrm{mg} / \mathrm{mL}, \log P=4.5$ ) [17], to enhance its dissolution profile. Further, the effect of SNEDDS components (oil; Peceol, surfactant; Tween 80 , and co-surfactant; Transcutol P) on various response variables like SNEDDS globule size, their \% transmittance, Self emulsification time, Dissolution (\% drug release) after $5 \mathrm{~min}$ and $40 \mathrm{~min}$ was also assessed.

\section{Methods \\ Materials}

Ezetimibe was obtained from Jubliant Generics Limited as a kind gift sample. Peceol, Maisine 35-1, Labrafac Lipophile 
WL-1349, Labrafac PG, Capryol PGMC, Labrafil M2125, Lauroglycol 90, Labrasol ALF, and Transcutol P were received as gift samples by Gattefossé (Saint-Priest Cedex, France). Tween 80 (Polyoxyethylene 20 sorbitan monooleate) was supplied by Sigma-Aldrich Chemical Company, St. Louis, USA. All other chemicals used in this study were of analytical grade.

\section{Methods}

\section{Solubility studies (screening of excipients)}

The selection of excipients (oil, surfactant, and cosurfactants) was based on their ability to dissolve a maximal drug. Various oils (Peceol, Maisine 35-1, Labrafac Lipophile WL-1349 and Labrafac PG), surfactants (Tween 80 and Labrasol ALF), and co-surfactants (Capryol PGMC, Labrafil M2125, Lauroglycol 90, and Transcutol P) were screened on solubility basis using the shake-flask method. An excess quantity of EZT was added to each 2 $\mathrm{mL}$ of tested excipients in a test tube and these mixtures were thoroughly mixed using vortex shaker while maintaining the temperature at $37{ }^{\circ} \mathrm{C}$. Each of the systems was then centrifuged using high-speed centrifuge at 10,000 rpm for $10 \mathrm{~min}$. The supernatant portion of each system was separated and its drug content was estimated after suitable dilution with methanol at $233 \mathrm{~nm}$ using UVvisible spectrophotometer (UV-1800, Shimadzu Corporation, Tokyo, Japan) against blank (methanol). The study was conducted in triplicate and their mean values were recorded $[18,19]$.

\section{Construction of pseudoternary phase diagram}

For the identification of the optimal concentration of oil, surfactant, and co-surfactant for formulating SNEDDS and also to specify the existence of maximum selfemulsifying region, the pseudoternary phase diagram for all mixtures were constructed without incorporating drug using CHEMIX School 3_60 version. Based on the results acquired from preliminary solubilization study, components like oil, surfactant, and co-surfactant were utilized as apex of ternary phase diagram. The procedure reported by Craig et al. (1995) was used in this study [20]. Two batches were prepared, first comprised of Peceol as oil, Labrasol as surfactant, and Transcutol P as co-surfactant while the second batch contains Peceol as oil, Tween 80 as surfactant, and Transcutol P as co-surfactant. Surfactant:co-surfactant ratio (Smix) was prepared by mixing selected surfactant and co-surfactant in different volume ratios (1:1, 1:2, 2:1, 3:1, and 3:1.5). Each phase diagram was constructed by mixing oil and exact Smix in nine ratios (1:9, 2:8, 3:7, 4:6, 5:5, 6:4, 7:3, 8:2, 9:1; \%w/w). $0.3 \mathrm{~mL}$ of the mixture of oil, surfactant, and co-surfactant (ternary mixture) was gently stirred on a mechanical stirrer with $300 \mathrm{~mL}$ of distilled water in a glass beaker while maintaining the temperature at $37^{\circ} \mathrm{C}$. The propensity of the system to emulsify spontaneously and the spread of emulsion droplets were investigated. The emulsions were subjected to stand for $2 \mathrm{~h}$ and their transmittance was assessed at $638.2 \mathrm{~nm}$ by a double beam UV-Vis spectrophotometer (UV-1800, Shimadzu Corporation, Tokyo, Japan) using water as blank [20, 21].

\section{Box-Behnken experimental design}

A three-factor, three-level BBD was produced by software of experimental design (Design Expert 11). Among the various techniques of response surface methodology (RSM), Box-Behnken design (BBD) is a suitable approach for ascertaining the effects of formulation ingredients/variables (independent factors) and their associated effect on the response variables (dependent factors). BBD is a threefactor, three-level statistical screening approach which was applied in our study to evaluate main as well as interaction effects of the formulation variables (oil, surfactant, and cosurfactant concentrations or amounts) on measured responses of prepared SNEDDS and applicability of desirability function to optimize the formulation. BBD requires 15 experimental runs with 3 central points to determine the experimental error and the precision of the design [22]. The non-linear quadratic model equation produced by the BBD is of the form (Eq. 1):

$$
\begin{aligned}
Y= & \alpha_{0}+\alpha_{1} X_{1}+\alpha_{2} X_{2}+\alpha_{3} X_{3}+\alpha_{4} X_{1} X_{2} \\
& +\alpha_{5} X_{2} X_{3}+\alpha_{6} X_{1} X_{3}+\alpha_{7} X_{1}{ }^{2}+\alpha_{8} X_{2}{ }^{2} \\
& +\alpha_{9} X_{3}{ }^{2}
\end{aligned}
$$

where, $Y$ is the dependent or measured response of the dependent variables associated with each factor-level combination; $\alpha_{0}$ is the intercept; $\alpha_{1}-\alpha_{9}$ are the regression coefficients; while the independent variables used in the studied is denoted by $X_{1}, X_{2}$, and $X_{3}$, which were listed in Table 1.

The amounts of oil, surfactant, and co-surfactant in each of the 15 formulations were given in Table 2.

\section{Preparation of ezetimibe-loaded SNEDDS}

After studying pseudoternary phase diagram, selfemulsifying region was identified and the concentrations of surfactant (20-60\%), co-surfactant $(10-30 \%)$, and oil (10$70 \%$ ) were selected to prepare the drug-loaded formulations. Fifteen formulations were formed incorporating ezetimibe at a concentration of $10 \mathrm{mg} / \mathrm{g}$. First, the drug was dissolved in the co-surfactant, followed by the addition of an appropriate amount of surfactant. After proper mixing, the oil component was then added into the homogenized mixture. All the components were mixed gently using vortex shaker and were then warmed at $40{ }^{\circ} \mathrm{C}$ on a magnetic stirrer until a clear homogenized mixture was obtained. The preconcentrate remained clear at room temperature and was kept for further study. 
Table 1 Variables in the Box-Behnken design

\begin{tabular}{llll}
\hline S.no. & Independent variables & Dependent variables & Goal for dependent variables \\
\hline 1. & Amount of oil added $\left(X_{1}\right)$ & Globule size $\left(Y_{1}\right)$ & Minimize \\
2. & Amount of surfactant added $\left(X_{2}\right)$ & Percentage transmittance $\left(Y_{2}\right)$ & Maximize \\
3. & Amount of co-surfactant added $\left(X_{3}\right)$ & Self-emulsification time $\left(Y_{3}\right)$ & Minimize \\
4. & - & Dissolution after 5 minutes $\left(Y_{4}\right)$ & Maximize \\
5. & - & Dissolution after 40 minutes $\left(Y_{5}\right)$ & Maximize \\
\hline
\end{tabular}

\section{Evaluation of SNEDDS}

\section{Droplet size and zeta potential determination}

The average droplet size, zeta potential, and polydispersity index (PDI) of the prepared 15 formulations (F1-F15) containing the drug were determined using

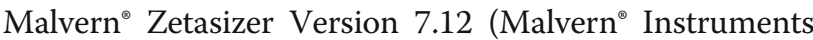
Limited, Worcestershire, UK). Prior to the measurement, sample from each formulation was diluted with distilled water in the ratio of 1:100 and agitated gently to ensure proper distribution of the formulation in aqueous media. All the measurements were taken in triplicate.

Table 2 Design layout of Box-Behnken design batches for prepared SNEDDS

\begin{tabular}{llll}
\hline Experimental run & \multicolumn{3}{l}{ Coded factor levels } \\
& Factor $\mathbf{1}\left(\boldsymbol{X}_{\mathbf{1}}\right)$ & Factor $\mathbf{2}\left(\boldsymbol{X}_{\mathbf{2}}\right)$ & Factor $\mathbf{3}\left(\boldsymbol{X}_{\mathbf{3}}\right)$ \\
1 & 0 & 0 & 0 \\
2 & 0 & 1 & -1 \\
3 & 1 & -1 & 0 \\
4 & 0 & -1 & -1 \\
5 & 0 & 0 & 0 \\
6 & 1 & 0 & -1 \\
7 & 1 & 0 & 1 \\
8 & -1 & 1 & 0 \\
9 & 1 & 1 & 0 \\
10 & -1 & 0 & -1 \\
11 & 0 & 0 & 0 \\
12 & -1 & 0 & 1 \\
13 & 0 & 1 & 1 \\
14 & 0 & -1 & 1 \\
15 & -1 & -1 & 0
\end{tabular}

Translation of coded levels in actual units

\begin{tabular}{llll} 
Coded levels & Low* & Middle* & High* \\
& -1 & 0 & 1 \\
$\begin{array}{l}\text { Factor } 1\left(X_{1}\right) \\
\text { (Amount of oil) }\end{array}$ & $10 \%$ & $40 \%$ & $70 \%$ \\
$\begin{array}{l}\text { Factor } 2\left(X_{2}\right) \\
\text { (Amount of surfactant) }\end{array}$ & $20 \%$ & $40 \%$ & $60 \%$ \\
$\begin{array}{l}\text { Factor } 3\left(X_{3}\right) \\
\text { (Amount of co-surfactant) }\end{array}$ & $10 \%$ & $20 \%$ & $30 \%$ \\
\hline
\end{tabular}

*Low, middle, and high-coded levels were chosen on the basis of preliminary trials conducted and pseudoternary diagrams constructed for efficient percentage transmittance.

\section{Percentage transmittance (\% T)}

In order to measure the \% transmittance of the EZTloaded SNEDDS, $0.1 \mathrm{~mL}$ of the formulation was added to $100 \mathrm{~mL}$ of distilled water with continuous stirring and the diluted formulation was analyzed by double beam UV-Vis spectrophotometer at $638.2 \mathrm{~nm}$. The study was conducted in triplicate.

\section{Self-emulsification time}

All the prepared formulations were monitored visually for their self-emulsification time which is the time needed by the SNEDDS to form homogeneous dispersion on dilution with an aqueous medium. Briefly, in a standard USP type II dissolution apparatus containing phosphate buffer (250 $\mathrm{mL}, \mathrm{pH}$ 6.8), $1 \mathrm{~mL}$ of each formulation was added dropwise. The speed of paddle was maintained to $50 \mathrm{rpm}$ to provide gentle agitation and the temperature was kept at $37 \pm 0.5^{\circ} \mathrm{C}$. The resulting system was visually observed for the formation of nanoemulsion. The time which was required by the SNEDDS for thorough dispersion in buffer was recorded as self-emulsification time.

\section{Dissolution study}

Drug-release studies for the 15 SNEDDS formulations were done using USP XXIII dissolution apparatus I (basket type) with phosphate buffer ( $\mathrm{pH} 6.8,900 \mathrm{~mL}$ ) as the medium at $37 \pm 0.5{ }^{\circ} \mathrm{C}$. The rotation speed of the basket was adjusted to $50 \mathrm{rpm}$. Then, $0.5 \mathrm{~g}$ of the EZT-loaded SNEDDS formulations (equivalent to $5 \mathrm{mg}$ of EZT) was placed in hard gelatin capsules, size "0." At predetermined time intervals, an aliquot $(3 \mathrm{~mL})$ of the sample was collected, filtered, and analyzed for EZT contents by double beam UV-Vis spectrophotometer measured at $233 \mathrm{~nm}$. An equivalent volume $(3 \mathrm{~mL})$ of fresh dissolution medium was immediately added to keep the sink condition. Moreover, drug release profile from a suspension of pure EZT (in carboxymethyl cellulose) was also observed and compared with that of prepared EZT-SNEDDS formulations. The dissolution studies were performed in triplicate.

\section{Optimization using desirability function}

In the study, all the five responses were simultaneously optimized using a numerical optimization technique (desirability function approach) given by Derringer and Suich 
[23]. In this approach, a specific goal was assigned to each response (Table 1). A partial desirability function is associated with an individual response, where value 0 is assigned to an undesired/unacceptable response while for an acceptable response, the value lies between 0 and 1 . The value between 0 and 1 indicates the closeness of the response to its target value (i.e., minimum to most desirable. Therefore, the desirability function helps in ascertaining the most favorable and appropriate point in the design space that accomplishes the set goals for dependent variables (response). In our study, Design Expert 11 was utilized to conclude the maximum desirability value after assigning desired goals to the responses.

\section{Evaluation of optimized formulation}

\section{Effect of composition of optimized formulation on response} variables

On the basis of desirability function, optimized formulation (FF1) was selected and prepared. The prepared optimized formulation was assessed for the parameters/response variables (globule size, percentage transmittance, self-emulsification time, dissolution after $5 \mathrm{~min}$ and $40 \mathrm{~min}$ ), in accordance with the above-mentioned procedure. The observed responses for the optimized formulation were compared with that of predicted values. The other parameters like robustness to dilution, cloud point measurement, and stability studies were also conducted for FF1.

\section{Robustness to dilution}

Different dissolution media (distilled water, $0.1 \mathrm{M} \mathrm{HCl}$ buffer ( $\mathrm{pH}$ 1.2) and phosphate buffer ( $\mathrm{pH}$ 6.8)) were used to dilute the optimized formulation to 10,100 , and 1000 times. The diluted samples were checked for any occurrence of instability (phase separation or precipitation) after storing for $24 \mathrm{~h}$.

\section{Cloud point measurement}

The cloud point measurement was done to assess the stability of EZT-loaded SNEDDS at physiological temperature as in the case of in vivo. The cloud point value of optimized SNEDD formulations was determined. The formulation was diluted 100 times with distilled water and placed on a water bath with a gradual increase in temperature (approximately $2{ }^{\circ} \mathrm{C} / \mathrm{min}$, range 25 to $80{ }^{\circ} \mathrm{C}$ ). The cloud point was recorded as the point of temperature at which an abrupt appearance of the cloudiness was observed visually [24].

\section{Transmission electron microscopy}

The morphological characteristic of the optimized formulation (FF1) of EZT was evaluated by transmission electron microscopy (TEM) (Hitachi H-7500). Prior to the measurement, the sample of the optimized formulation was diluted with distilled water (1:100) and agitated gently to assure proper dispersion of the formulation. The reconstitution of the formulation was followed by negative staining using a phosphotungstic acid solution.

\section{Stability studies of optimized SNEEDS}

The thermodynamic stability and phase integrity of the optimized formulation was assessed under variable conditions of temperature and centrifugal force [25]. The effect of temperature and centrifugal force was studied by subjecting the optimized formulation to the following test [26]:

Centrifugal test In this study, centrifugation (5000 rpm for $30 \mathrm{~min}$ ) of the optimized formulation was done after diluting with distilled water (1:25). The nanoemulsion was then checked for any sign of instability like phase separation, creaming, etc. [27].

Heating-cooling cycles The preconcentrate of optimized SNEDDS was subjected to three cycles of heating and cooling by storing the formulation between $4{ }^{\circ} \mathrm{C}$ and $45{ }^{\circ} \mathrm{C}$ for not less than $48 \mathrm{~h}$ at each temperature. Then, the formulation was initially assessed for drug precipitation and phase separation followed by its dilution with distilled water. The obtained nanoemulsion was then checked for instability [28].

Freeze-thaw cycle This involved three freeze-thaw cycles in which formulation was stored between $-20{ }^{\circ} \mathrm{C}$ and + $25{ }^{\circ} \mathrm{C}$ for not less than $48 \mathrm{~h}$ at each temperature. Then, centrifugation of the formulation was done for $5 \mathrm{~min}$ at 3000 and then the formulation was visually inspected for phase separation and drug precipitation. Similarly, as discussed above, formulation was then diluted with distilled water and examined for some instability [28].

\section{Results}

\section{Solubility studies}

The excipients used in the preparation of SNEDDS should be able to solubilize maximum drug as well as they should exhibit a larger self-emulsification region in the pseudoternary phase diagram. The excipients were chosen on the basis of solubilizing capacity, their safety, and compatibility with the incorporated drug. The equilibrium solubility of EZT in different excipients is represented in Fig. 1.

In our study, four oils were examined to use as lipid phase in the preparation of SNEDDS. It was evident from the study that EZT showed the highest solubility in Peceol $(11.75 \pm 1.63 \mathrm{mg} / \mathrm{mL})$ and Maisine 35-1 (12.25 \pm $1.78 \mathrm{mg} / \mathrm{mL}$ ) and the least was observed in Labrafac PG and Labrafac lipophile WL-1349.

In our study, two non-ionic surfactants (Labrasol ALF and Tween 80) were used. Both surfactants showed reasonable solubilizing potential for EZT and also possess high HLB value (Labrasol ALF- 12 and Tween 80-15). Hence, both the surfactants were selected for delineating a stable nanoemulsion region. 


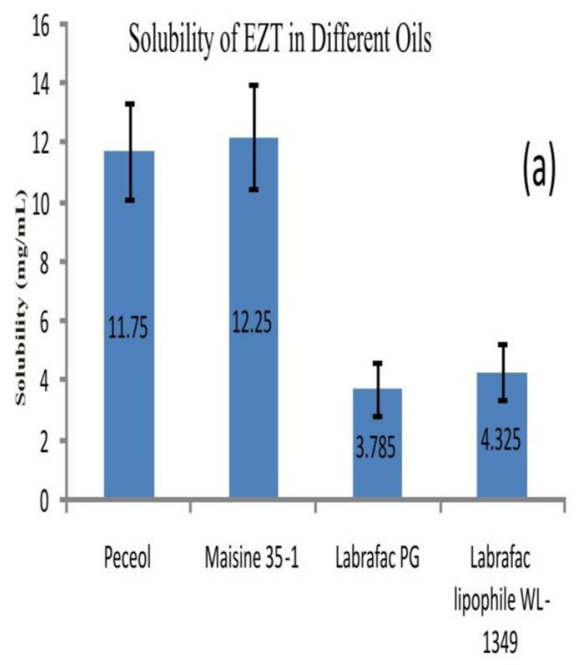

Oils
Solubility of EZT in Differernt Surfactants

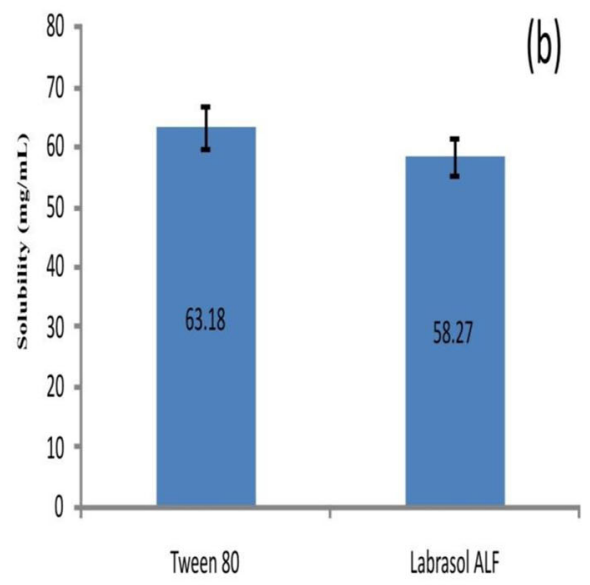

Surfactants

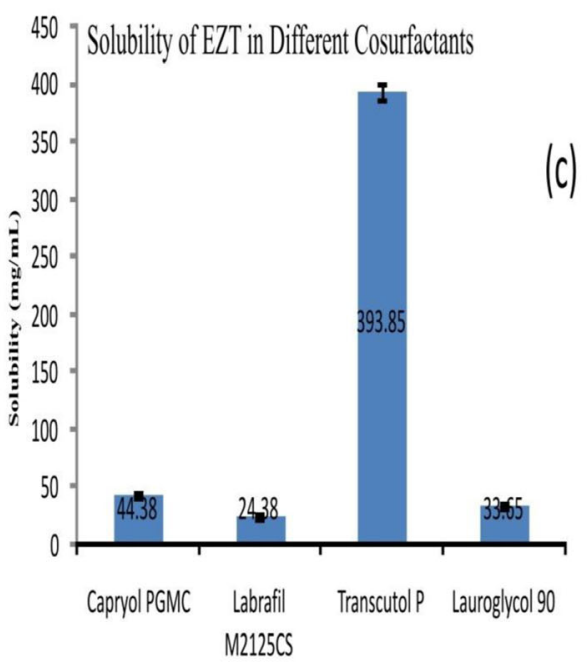

Cosurfactants

Fig. 1 Solubility of ezetimibe in different excipients. a Oils, b surfactants, c co-surfactants. All values are mean $\pm s d, n=3$

Co-surfactants are the substance which helps the surfactants in solubilization of drug and hence the one which shows maximum solubility of EZT was chosen. Among the co-surfactants, Transcutol P was selected as it showed maximum solubility of EZT $(>393.85 \pm 6.74 \mathrm{mg} / \mathrm{mL}$ ).

\section{Pseudoternary phase diagram}

On the basis of preliminary trials on the drug solubility in various vehicles, Peceol (oil), Labrasol and Tween 80 (surfactant), and Transcutol P (co-surfactant) were selected for the development of pseudoternary phase diagrams of the three systems (with different surfactant and cosurfactant ratio). Two batches were prepared, batch $\mathrm{A}$ comprised of Peceol as oil, Labrasol as surfactant, and
Transcutol P as co-surfactant, while batch B contains Tween 80 as surfactant instead of Labrasol ALF (while other two components were same as batch A). The phase diagram gives the relationship between the concentration range of components and their phase behavior in the formation of nanoemulsion.

Based on the result of percentage transmission and visual appearance first batch (batch A) containing Peceol, Labrasol ALF, and Transcutol P was rejected as the percentage transmittance was low and appeared turbid, (Supplementary Tables 1 and 2), which revealed the formation of coarse emulsion instead of nanoemulsion.

The pseudoternary phase diagrams for batch B containing Peceol, Tween 80 and Transcutol P, were shown in 
Fig. 2. Figure $2 \mathrm{a}-\mathrm{e}$ represents five systems $(\mathrm{I}-\mathrm{V})$ having different Smix ratios. The shaded area in Fig. 2 represents the nanoemulsifying regions. From Fig. 2e, it was clearly observed that system $\mathrm{V}$ displayed a broader nanoemulsification region as compared to other four systems. The Smix concentration of system $\mathrm{V}$ which is $3: 1.5 \mathrm{w} / \mathrm{w}$, produced nanoemulsion which can emulsify up to $60 \% \mathrm{w} / \mathrm{w}$ of an oily composition. However, systems I, II, and III with Smix concentration of 1:1, 1:2, and 2:1, respectively, produced clear emulsion and found to emulsify only $20 \%$ (for system I) and 30\% (for systems II and III) of the oil phase. Moreover, it was noticed that surfactant concentration below $40 \% \mathrm{w} / \mathrm{w}$ resulted in the turbid emulsion for systems I and III, while system V produced transparent stable nanoemulsion with a good percentage of transmittance at even $20 \% \mathrm{w} / \mathrm{w}$ of surfactant.

The system IV containing Smix at a concentration of $3: 1$ was able to emulsify $40 \%$ of oil, but the low level of co-surfactant in this system renders the system inefficient to emulsifying more amount of oil.

On the basis of range of nanoemulsion formation in the phase diagram of system $\mathrm{V}$ (Fig. 2e), the constraints of independent variables $\left(10 \% \leq\right.$ Oil $\left(\mathrm{X}_{1}\right) \leq 70 \%, 20 \%$ $\leq$ Surfactant $\left(\mathrm{X}_{2}\right) \leq 60 \%, 10 \% \leq$ Co-surfactant $\left.\left(\mathrm{X}_{3}\right) \leq 30 \%\right)$ were selected for further optimization.

\section{Experimental design}

In the present investigation, BBD was selected and applied to analyze the consequence of three independent variables (components of SNEDDS) on dependent variables. The constraints of the dependent and independent factors are depicted in Tables 1 and 2. As per the BBD, 15 formulations were formulated and assessed for their response variables, i.e., globule size $\left(Y_{1}\right)$, percentage transmittance $\left(Y_{2}\right)$, self-emulsification time $\left(Y_{3}\right)$, dissolution after $5 \mathrm{~min}\left(Y_{4}\right)$, and dissolution after $40 \mathrm{~min}$ $\left(Y_{5}\right)$.

All data were obtained using Design Expert 11. Each response was separately fitted to a full quadratic equation; significance of model was assessed by ANOVA, lack of fit test, and multiple correlation coefficient $\left(R^{2}\right)$ test. For the model to be fitted well in the quadratic equation, the model $p$ value should be less than 0.05 (significant). The variation of data around the fitted value is analyzed by lack of fit test and it should be insignificant ( $p$ value $>0.05)$ relative to the pure error. The amount of variation around the mean is expressed by $R^{2}$ value (multiple correlation coefficient test). The value of $R^{2}$ should be close to 1 [29].

\section{Evaluation of SNEDDS \\ Globule size, zeta potential, and effect of formulation composition on globule size $\left(Y_{1}\right)$}

Emulsion globular size is considered to be an important factor because it governs the rate and extent of drug release and absorption [30]. The globule size, PDI, and zeta potential of the formulations were measured using Malvern Zeta sizer and the results obtained are depicted in Table 3.

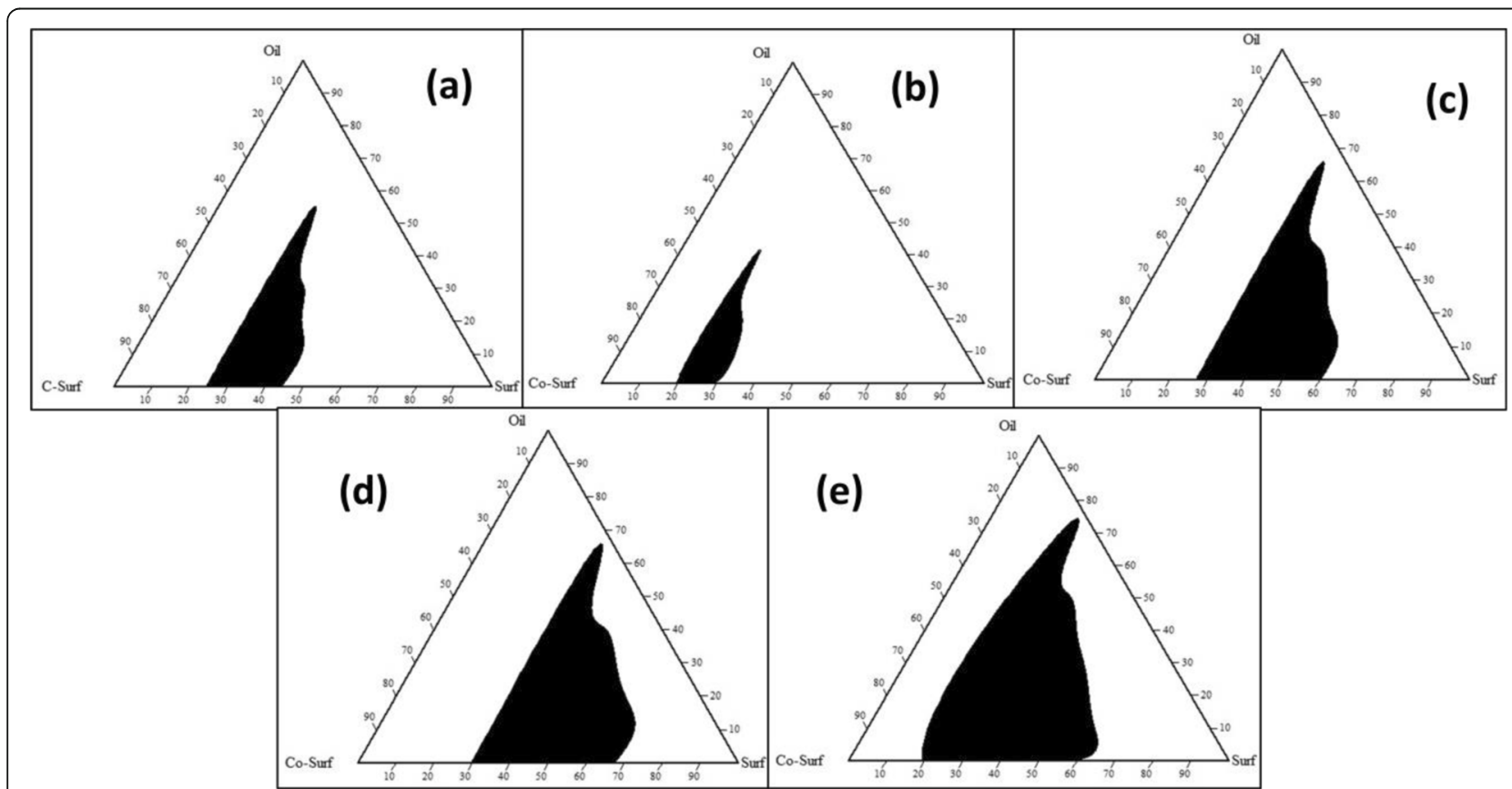

Fig. 2. Ternary phase diagrams of different selected systems. The shaded area represents the self-nanoemulsion region. a System I with 1:1 Smix. b System II with 1:2 Smix. c System III with 2:1 Smix. d System IV with 3:1 Smix. e System V with 3:1.5 Smix 
The globule size of EZT-SNEDDS was found to range between 24.4 (Fig. 3) and $102.01 \mathrm{~nm}$. It was clear from the results that there was a remarkable diminution in globule size with an increased concentration of surfactant and decreased concentration of oil.

The PDI is a dimensionless quantity which measures the width of the size distribution and its value lies between 0 and 1 . Values close to 0 indicate a monodisperse system while greater values indicate a heterogeneous system with broader size distribution. All the 15 formulations showed PDI below 0.3, indicating a good globular size uniformity of the prepared system [31].

Zeta potential (Table 3) obtained from the present investigation revealed that zeta potential varies between - 11.2 to $-27.1 \mathrm{mV}$.

Based on the BBD, the independent factor combinations of Peceol $\left(X_{1}\right)$, Tween $80\left(X_{2}\right)$, and Transcutol $\mathrm{P}$ $\left(X_{3}\right)$ resulted in different response variables for globule size $\left(Y_{1}\right)$. The mathematical relationship in the form of a polynomial equation for the measured response (globule size), $Y_{1}$, is mentioned below (Eq. 2):

$$
\begin{aligned}
Y_{1} \text { (Globule size) } & \\
= & 47.86+1.040 X_{1}-0.020 X_{2}-0.694 X_{3} \\
& -0.00126 X_{1} X_{2}+0.00701 X_{2} X_{3} \\
& -0.00092 X_{1} X_{3}+0.00259 X_{1}^{2} \\
& +0.00439 X_{2}^{2}-0.0176 X_{3}^{2}
\end{aligned}
$$

The above equation reflect the quantitative effect of independent variables $\left(X_{1}-X_{3}\right)$ and their interactions (coefficient with more than one-factor term, $X_{1} X_{2}, X_{1} X_{3}$, $\left.X_{2} X_{3}\right)$ on the response $Y_{1}$. The $p$ value $(<0.05)$ of the coefficient indicated their significant effect on $Y_{1}$ (Table 4). The positive sign of coefficient signifies collegial effect while the negative sign signifies the opposing effect of independent variables on response. The larger coefficient value of the factor indicates their substantial effect on the response. All responses were fitted well to the quadratic model. The efficiency of the model was verified by ANOVA and multiple correlation test $\left(R^{2}\right)$. The result of ANOVA and multiple correlation test $\left(R^{2}\right)$ of the quadratic model is shown in Table 4. The $p$ value and $R^{2}$ value was found to be $<0.05$ and 0.9965 , respectively. The observed $p$ value $(<0.05)$ and $R^{2}$ value (close to 1 ) confirmed that independent variables had a significant effect in predicting the response $\left(Y_{1}\right)$. In addition, the multicollinearity of the independent factors was assessed by variance inflation factor (VIF) and it was found that there was no multi-collinearity amid the independent variables $\left(X_{1}-X_{3}\right)$ in the quadratic model, as the value VIF is less than 10 (VIFs greater than 1 indicate multi-collinearity. As a general rule, VIFs less than 10 are tolerable).

The response surface plot, contour plots, and predicted vs actual plot for $Y_{1}$ between $X_{1}$ and $X_{2}$ at middle levels of $X_{3}$ are depicted in Figs. 4a, 5a, and 6a, respectively.

\section{Percentage transmittance and effect of formulation composition on percentage transmittance $\left(Y_{2}\right)$}

Percentage transmittance was studied to ascertain that

\begin{tabular}{|c|c|c|c|c|c|c|c|c|}
\hline Run & Formula-tion code & $\begin{array}{l}\text { Globule size }(\mathrm{nm}) \\
\left(Y_{1}\right)\end{array}$ & PDI & Zeta potential (mV) & $\begin{array}{l}\text { Transmittance } \\
(\%) \\
\left(Y_{2}\right)\end{array}$ & $\begin{array}{l}\text { Self-emulsification } \\
\text { time }(\mathrm{sec}) \\
\left(Y_{3}\right)\end{array}$ & $\begin{array}{l}\% \text { drug release } \\
\text { after } 5 \text { min } \\
\left(Y_{4}\right)\end{array}$ & $\begin{array}{l}\% \text { drug release } \\
\text { after } 40 \text { min } \\
\left(Y_{5}\right)\end{array}$ \\
\hline 1 & F1 & $55.3 \pm 3.08$ & 0.275 & $-25.5 \pm 6.46$ & $100.1 \pm 3.46$ & $90 \pm 1.33$ & $38.17 \pm 2.64$ & $70.54 \pm 3.54$ \\
\hline 2 & F2 & $45.7 \pm 2.89$ & 0.287 & $-23.9 \pm 5.81$ & $100.8 \pm 2.94$ & $82 \pm 2.54$ & $40.27 \pm 2.98$ & $75.62 \pm 3.02$ \\
\hline 3 & F3 & $102.1 \pm 8.88$ & 0.444 & $-17 \pm 4.73$ & $93.8 \pm 5.61$ & $182 \pm 4.67$ & $32.22 \pm 2.11$ & $58.21 \pm 2.14$ \\
\hline 4 & $\mathrm{~F} 4$ & $76.8 \pm 3.65$ & 0.298 & $-22.9 \pm 4.81$ & $97.2 \pm 4.32$ & $145 \pm 5.12$ & $36.19 \pm 2.14$ & $66.72 \pm 2.11$ \\
\hline 5 & F5 & $55.8 \pm 2.14$ & 0.299 & $-26.2 \pm 3.35$ & $100.3 \pm 2.54$ & $94 \pm 3.31$ & $39.85 \pm 2.13$ & $71.29 \pm 2.56$ \\
\hline 6 & F6 & $89.9 \pm 3.57$ & 0.302 & $-18.3 \pm 3.37$ & $98.2 \pm 2.15$ & $170 \pm 4.98$ & $33.29 \pm 1.97$ & $60.16 \pm 2.81$ \\
\hline 7 & F7 & $81.83 \pm 2.68$ & 0.271 & $-23.9 \pm 6.38$ & $98.5 \pm 3.68$ & $125 \pm 4.41$ & $34.09 \pm 2.56$ & $63.45 \pm 2.49$ \\
\hline 8 & F8 & $24.4 \pm 2.07$ & 0.247 & $-26.4 \pm 6.52$ & $101.2 \pm 1.97$ & $55 \pm 3.54$ & $49.21 \pm 2.99$ & $95.27 \pm 2.38$ \\
\hline 9 & F9 & $76.2 \pm 3.02$ & 0.315 & $-24 \pm 5.15$ & $97.4 \pm 2.41$ & $118 \pm 2.63$ & $34.62 \pm 3.03$ & $65.81 \pm 2.62$ \\
\hline 10 & F10 & $31.8 \pm 2.15$ & 0.276 & $-26.3 \pm 2.48$ & $99.3 \pm 3.15$ & $67 \pm 1.14$ & $43.18 \pm 2.91$ & $84.21 \pm 2.51$ \\
\hline 11 & F11 & $56 \pm 3.27$ & 0.322 & $-26.1 \pm 3.64$ & $100.2 \pm 4.81$ & $97 \pm 1.89$ & $39.13 \pm 2.10$ & $70.85 \pm 1.45$ \\
\hline 12 & $\mathrm{~F} 12$ & $32.2 \pm 2.08$ & 0.259 & $-16.6 \pm 3.52$ & $98.1 \pm 3.12$ & $68 \pm 2.14$ & $45.69 \pm 2.13$ & $91.23 \pm 3.05$ \\
\hline 13 & F13 & $38.8 \pm 2.45$ & 0.268 & $-27.1 \pm 5.88$ & $97.9 \pm 3.65$ & $85 \pm 3.05$ & $41.56 \pm 1.95$ & $78.26 \pm 2.33$ \\
\hline 14 & F14 & $63.91 \pm 3.91$ & 0.308 & $-11.2 \pm 3.52$ & $97.6 \pm 2.88$ & $105 \pm 2.54$ & $37.02 \pm 3.13$ & $68.61 \pm 2.84$ \\
\hline 15 & F15 & $38.4 \pm 2.31$ & 0.302 & $-21.7 \pm 5.08$ & $98.7 \pm 2.69$ & $70 \pm 2.96$ & $42.17 \pm 2.52$ & $82.24 \pm 2.08$ \\
\hline
\end{tabular}
the nanoemulsion formed was transparent and clear. Clear solution/dispersions give higher transmittance while the cloudier/turbid solutions/dispersion give lower

Table 3 Observed responses from randomized runs in the Box-Behnken design 


\section{Size Distribution by Number}

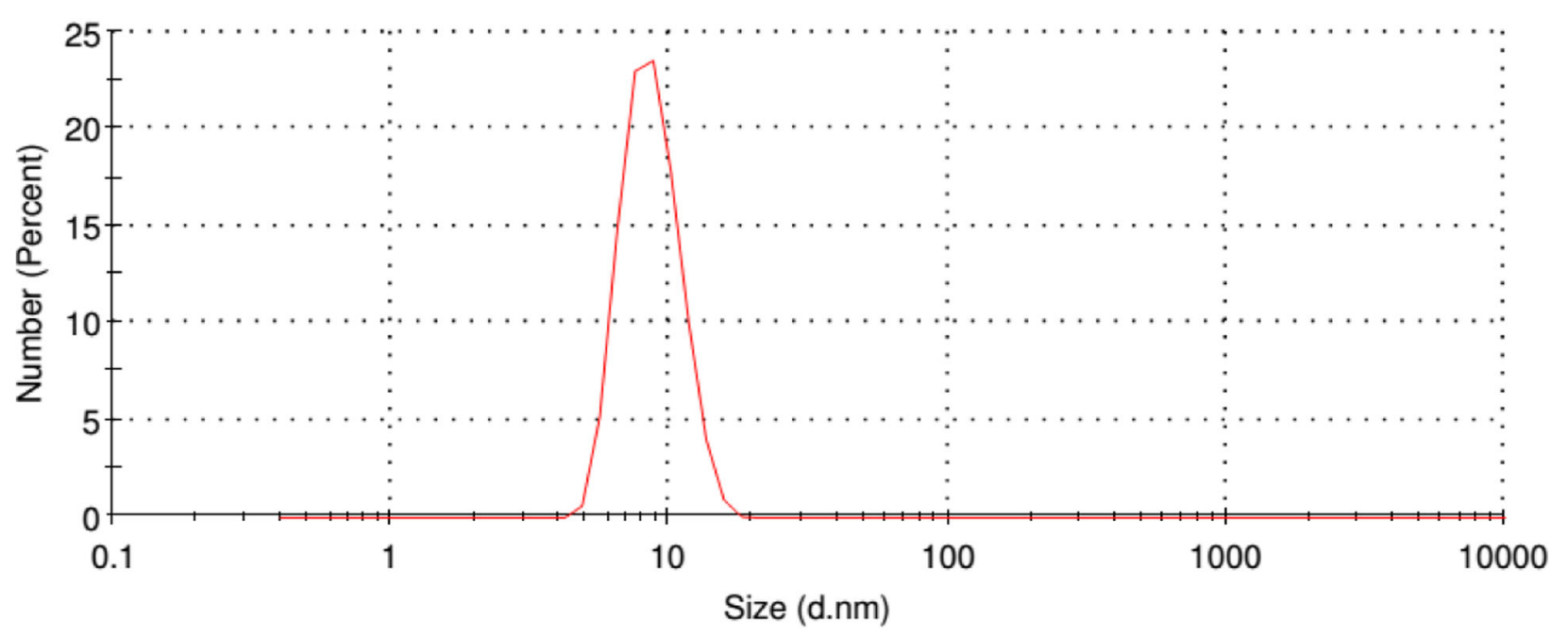

Record 1: Nano emulsion 1

Fig. 3 Globule size distribution of F8 formulation

transmittance, as the latter will scatter more of incident radiations resulting in lower transmittance. The result of percentage transmittance lies between 80.4 and $102.8 \%$. It was observed that percentage transmittance increases with a decrease in oil content and an increase in the content of Smix, respectively.

The full quadratic polynomial equation for the measured response (percentage transmittance), $Y_{2}$ is given below (Eq. 3):

$$
\begin{aligned}
Y_{2} & (\% \text { transmittance }) \\
= & 94.71-0.1679 X_{1}+0.1749 X_{2}+0.054 X_{3} \\
& +0.000042 X_{1} X_{2}-0.00162 X_{2} X_{3} \\
& -0.00008 X_{1} X_{3}-0.001349 X_{1}{ }^{2} \\
& -0.000160 X_{2}{ }^{2}+0.00136 X_{3}{ }^{2}
\end{aligned}
$$

The above equation showed a good fit to the response variable $\left(Y_{2}\right)$ as the $R^{2}$ of 0.9965 is in consonance with the adjusted $R^{2}$ of 0.9903 . The result of regression analysis for $Y_{2}$ depicted negative sign for $X_{1}$ (oil) and positive sign for $X_{2}$ (surfactant) and $X_{3}$ (cosurfactant). This suggested that with a decrease in the amount of oil (Peceol) and an increase in surfactant (Tween 80) and co-surfactant (Transcutol P) concentration, the \% transmittance increases. ANOVA analysis of the model equation generated suggested that the independent variables had significantly affected $(p<0.05)$ in predicting the response $\left(Y_{2}\right)$. F8 exhibited a higher percentage of transmittance (102.8\%). The result of the response plot, contour plot, and predicted vs actual plot are illustrated in Figs. 4b, 5b, and 6b, respectively. The increase in percentage transmittance with a decrease in oil content could be due to the presence of a large amount of emulsifier for the emulsification process [17].

\section{Self-emulsification time and effect formulation composition} on self-emulsification time $\left(Y_{3}\right)$

The result of self-emulsification time study is presented in Table 3. It was observed that the emulsification time vary from 55 to $182 \mathrm{~s}$.

The full quadratic polynomial equation for the measured response (self-emulsification time), $Y_{3}$ is given below (Eq. 4):

$$
\begin{aligned}
Y_{3} \text { (Self-Emulsification Time) } \\
=134.7+2.275 X_{1}-2.204 X_{2}-3.996 X_{3} \\
\quad-0.02042 X_{1} X_{2}+0.05375 X_{2} X_{3} \\
\quad-0.03833 X_{1} X_{3}-0.00880 X_{1}{ }^{2} \\
\quad-0.01167 X_{2}{ }^{2}+0.0592 X_{3}{ }^{2}
\end{aligned}
$$

The above polynomial equation represents the quantitative effect of predictor variables (independent variables) on the measured response $\left(Y_{3}\right)$. Since the $R^{2}$ value of 0.9970 is in close agreement with the adjusted $R^{2}$ of 0.9915 (as the difference is less than 0.2), the above equation showed a good fit to the response variable $\left(Y_{3}\right)$. The result of regression analysis for $Y_{3}$ showed a positive sign for $X_{1}$ (oil) and a negative sign for $X_{2}$ (surfactant) 
Table 4 Values of the regression coefficient $\left(a_{1}-a_{9}\right)$ and associated probability ( $p$ value* for each measured responses

\begin{tabular}{|c|c|c|c|c|c|}
\hline \multirow[t]{2}{*}{ Coefficient } & \multicolumn{5}{|l|}{ Response } \\
\hline & $Y_{1}(\mathrm{~nm})$ & $Y_{2}(\%)$ & $Y_{3}(s)$ & $Y_{4}(\%)$ & $Y_{5}(\%)$ \\
\hline$a_{0}$ & 47.86 & 94.71 & 134.7 & 36.63 & 81.40 \\
\hline$a_{1}$ & +0.1040 & -0.1679 & +2.275 & -0.1218 & -0.5950 \\
\hline$p$ value & 0.000 & 0.000 & 0.000 & 0.000 & 0.000 \\
\hline$a_{2}$ & -0.020 & +0.1749 & -2.204 & +0.1585 & +0.114 \\
\hline$p$ value & 0.000 & 0.000 & 0.000 & 0.000 & 0.000 \\
\hline$a_{3}$ & -0.694 & +0.054 & -3.996 & +0.258 & +0.115 \\
\hline$p$ value & 0.027 & 0.143 & 0.000 & 0.052 & 0.004 \\
\hline$a_{4}$ & -0.00126 & +0.000042 & -0.02042 & -0.001933 & -0.002263 \\
\hline$p$ value & 0.512 & 0.942 & 0.001 & 0.028 & 0.047 \\
\hline$a_{5}$ & +0.00701 & -0.00162 & +0.05375 & +0.00057 & +0.00094 \\
\hline$p$ value & 0.248 & 0.364 & 0.002 & 0.773 & 0.732 \\
\hline$a_{6}$ & -0.00092 & -0.00008 & -0.03833 & -0.00142 & -0.0031 \\
\hline$p$ value & 0.808 & 0.942 & 0.001 & 0.308 & 0.131 \\
\hline$a_{7}$ & +0.00259 & -001349 & -0.00880 & +0.000449 & +0.003861 \\
\hline$p$ value & 0.091 & 0.016 & 0.007 & 0.351 & 0.001 \\
\hline$a_{8}$ & +0.00439 & -0.000160 & 0.01167 & +0.000253 & +0.00254 \\
\hline$p$ value & 0.176 & 0.857 & 0.050 & 0.807 & 0.118 \\
\hline$a_{9}$ & -0.0176 & +0.00136 & +0.0592 & -0.00391 & +0.00395 \\
\hline$p$ value & 0.176 & 0.705 & 0.023 & 0.365 & 0.496 \\
\hline \multicolumn{6}{|l|}{ Model statistics } \\
\hline$R^{2}$ & 0.9965 & 0.9965 & 0.9970 & 0.9911 & 0.9968 \\
\hline Adjusted $R^{2}$ & 0.9903 & 0.9903 & 0.9915 & 0.9751 & 0.9910 \\
\hline Model $F$ value & 160.05 & 160.00 & 183.37 & 61.86 & 172.90 \\
\hline Model $p$ value & $<0.0001$ & $<0.0001$ & $<0.0001$ & 0.0001 & $<0.0001$ \\
\hline Lack of fit $F$ value & 17.17 & 1.11 & 0.9797 & 0.6681 & 11.88 \\
\hline Lack of fit $p$ value & 0.0555 & 0.5056 & 0.5410 & 0.6459 & 0.0786 \\
\hline
\end{tabular}

${ }^{*} p<0.05$ indicate significant terms

and $X_{3}$ (cosurfactant). This suggested that with an increase in the amount of oil (Peceol) and a decrease in surfactant (Tween 80) and co-surfactant (Transcutol P) concentration, the self-emulsification time increases. ANOVA analysis of the model suggested that the independent variables had significantly affected $(p<0.05)$ in predicting the response $\left(Y_{3}\right)$ and the coefficient terms with $p$ value less than 0.05 had a significant effect on the prediction efficacy of the model. The result of the response plot, contour plot, and predicted vs actual plot are illustrated in Figs. 4c, 5c, and 6c, respectively.

\section{Dissolution studies and effect of formulation composition on dissolution after $5 \mathrm{~min}\left(Y_{4}\right)$ and after $40 \min \left(Y_{5}\right)$}

In the present investigation, in vitro drug release study was done using USP dissolution apparatus I. Each formulation (containing $5 \mathrm{mg}$ of drug) was filled in a hard gelatin capsule (size 0). Percent drug release in phosphate buffer $(\mathrm{pH}$ 6.8) was observed at different time intervals. The result of the study was illustrated in Fig. 7 It was observed that F8 showed the highest cumulative percent drug release $(49.21 \%$ after $5 \mathrm{~min}$ and $95.27 \%$ after $40 \mathrm{~min}$ of the study) while the lowest drug release was observed with the formulations containing a high percentage of oil (F3, F6, F7, F9). Despite this, all the formulations exhibited enhanced dissolution profile, as the highest amount of drug from the formulations was released within $1 \mathrm{~h}$. While drug release from EZT suspension (sodium carboxymethyl cellulose) was only $5.23 \%$ and $38.95 \%$ after 5 min and $1 \mathrm{~h}$ of the study. This indicates the feasibility of SNEDDS in improving the dissolution of poorly soluble drugs (EZT). 

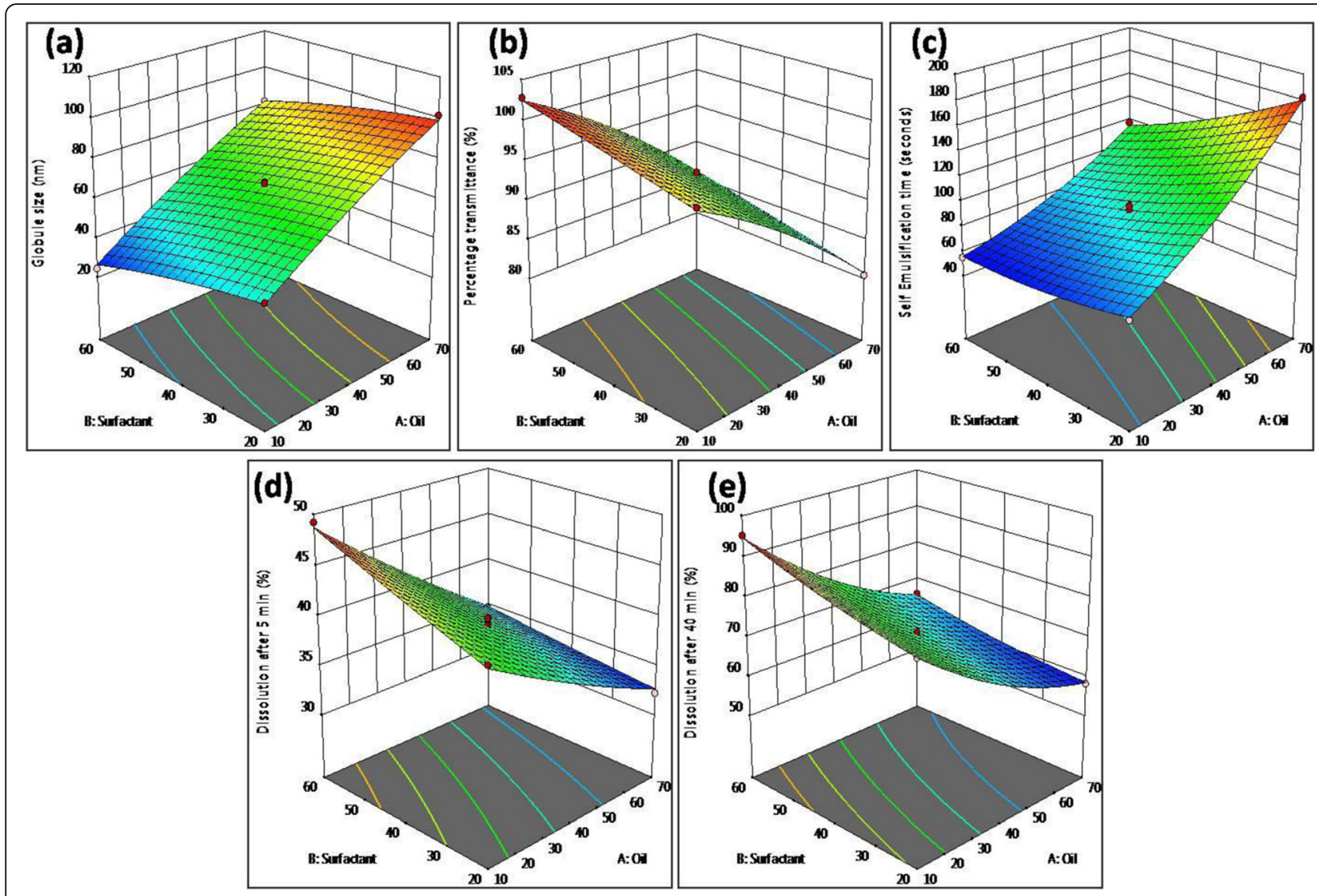

Fig. 4 Response surface plot representing the effects of $X_{1}$ and $X_{2}$ on the measured responses at the mid-level of $X_{3}$. a On globule size $\left(Y_{1}\right)$. b On $\%$ transmittance $\left(Y_{2}\right)$. c On self-emulsification time $\left(Y_{3}\right)$. d On dissolution (\% drug release) after 5 min $\left(Y_{4}\right)$. e On dissolution (\% drug release) after $40 \min \left(Y_{5}\right)$

The full quadratic polynomial equation for the measure response dissolution after $5 \mathrm{~min}\left(Y_{4}\right)$ is given below (Eq. 5):

$$
\begin{aligned}
& Y_{4}(\text { Dissolution after } 5 \mathrm{~min}) \\
&= 36.63-0.1218 X_{1}+0.1585 X_{2}+0.258 \mathrm{X}_{3} \\
&-0.001933 X_{1} X_{2}+0.00057 X_{2} X_{3} \\
&-0.00142 X_{1} X_{3}+0.000449 X_{1}{ }^{2} \\
&+0.000253 X_{2}{ }^{2}-0.00391 X_{3}{ }^{2}
\end{aligned}
$$

The above equation represents the effect of factors on response $Y_{4}$. It showed a goodness of fit to response variable as the $R^{2}$ of 0.9911 was in reasonable agreement with the adjusted $R^{2}$ of 0.97511 (difference is less than 0.2). Adequate precision ratio of 26.0612 depicts an adequate signal, confirming the utility of this model to navigate the design space. The result of regression analysis for $Y_{4}$ showed negative sign for oil and positive sign for surfactant and co-surfactant. This suggested antagonistic effect of oil (Peceol) content on response while surfactant (Tween 80) and co-surfactant (Transcutol P) showed synergistic effect on response. ANOVA analysis of the model suggested significant effect $(p<0.05)$ of independent factors $\left(X_{1}, X_{2}, X_{3}\right)$ in predicting the response.

The model graphs (response plot, contour plot and predicted vs actual plot) are shown in Figs. 4d, 5d, and 6d.

The full quadratic polynomial equation for the measured response (dissolution after $40 \mathrm{~min}$ ) $Y_{5}$ is given below (Eq. 6):

$$
\begin{aligned}
Y_{5} & \text { (Dissolution after } 40 \mathrm{~min}) \\
= & 81.40-0.5950 X_{1}+0.114 X_{2}+0.115 \mathrm{X}_{3} \\
& -0.002263 X_{1} X_{2}+0.00094 X_{2} X_{3} \\
& -0.00311 X_{1} X_{3}+0.003861 X_{1}{ }^{2} \\
& +0.00254 X_{2}{ }^{2}+0.00395 X_{3}{ }^{2}
\end{aligned}
$$

The above equation showed a goodness of fit to the response variable as the $R^{2}$ of 0.9968 was in reasonable agreement with the adjusted $R^{2}$ of 0.9910 (difference is less than 0.2 ). The result of the regression analysis for $Y_{5}$ shows a negative sign for oil and a positive sign for surfactant and co-surfactant. This suggested a antagonistic effect of oil content on response while surfactant and co-surfactant showed synergistic effect on response. The result of ANOVA analysis suggested a significant effect $(p<0.05)$ of 


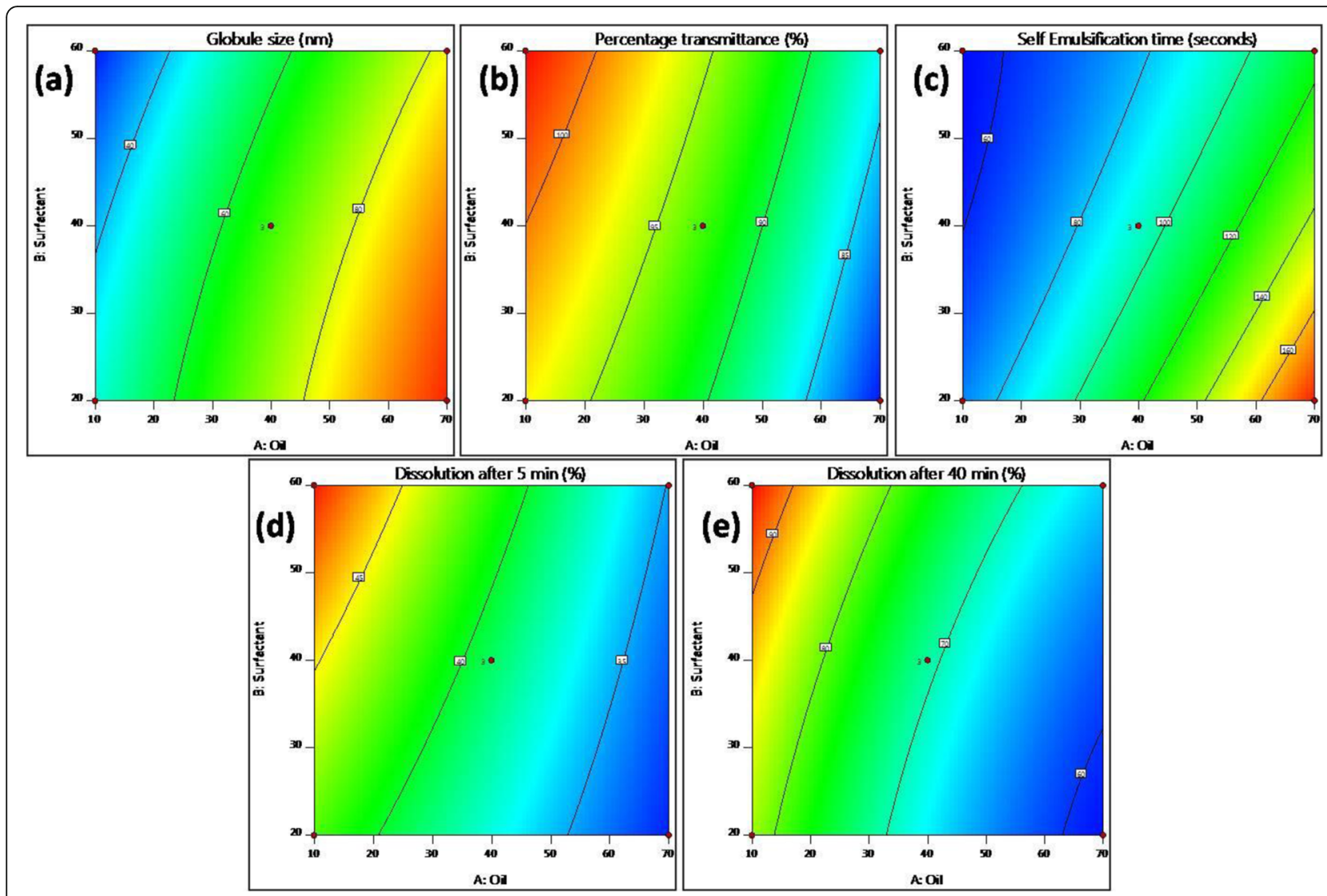

Fig. 5 Contour plot representing the effects of $X_{1}$ and $X_{2}$ on the measured responses at the mid-level of $X_{3}$. a On globule size $\left(Y_{1}\right)$. b On \% transmittance $\left(Y_{2}\right)$. c On self-emulsification time $\left(Y_{3}\right)$. d On dissolution (\% drug release) after 5 min $\left(Y_{4}\right)$. e On dissolution (\% drug release) after 40 $\min \left(Y_{5}\right)$

independent factors in predicting the response. The results were analogous with the above-discussed response $\left(Y_{4}\right)$.

The response surface plot and contour plots between factors $\left(X_{1}\right.$ and $\left.X_{2}\right)$ and their effect on response $\left(Y_{5}\right)$ are shown in Figs. 4e and 5e, respectively. The predicted vs actual plot showing the relation between actual and predicted response is shown in Fig. 6e. The 3D surface plot obtained was somewhat curvilinear.

\section{Identification and evaluation of optimum formulation using desirability function}

The desirability function approach was applied in the present study using Design Expert 11. The constraints were set for all the responses. The independent variables (factors) were set in range as depicted in Table 1. Among the responses, $Y_{1}$ and $Y_{3}$ were set to be minimized while $Y_{2}, Y_{4}$, and $Y_{5}$ were set to be maximized. Equal weight (1) and importance $(+++)$ were given to all responses (weight and importance are the constraints of the software used where 3 pluses $(+++)$ is a default setting which indicates equal importance of all responses). In the desirability function approach, individual desirability function is calculated which is required for combining all the responses in one measurement. This will help in forecasting the optimum levels for the independent factors [32]. Best formulation (FF1) with the best desirability function, fulfilling maximum requirement of response variables was selected. The selected optimized formulation contains $X_{1}=10 \% \mathrm{w} / \mathrm{w}, X_{2}=$ $60 \% \mathrm{w} / \mathrm{w}, X_{3}=27.12 \% \mathrm{w} / \mathrm{w}$, and the overall desirability was found to be 0.714 . The predicted value of the optimized formulation (FF1) for the response $Y_{1}, Y_{2}, Y_{3}, Y_{4}$, and $Y_{5}$ was $24.72 \mathrm{~nm}, 102.64 \%, 67.99 \mathrm{~s}, 49.39 \%$ and $97.12 \%$, respectively. To confirm and validate the optimization, optimized formulation was prepared in triplicate. All the responses were evaluated for each formulation as observed values. The comparison of the observed and predicted value is shown in Table 5. Figure 8 shows the counterplots for the desirability function between $X_{1}$ and $X_{2}\left(X_{3}\right.$ at an actual concentration of $27.12 \% \mathrm{w} / \mathrm{w})$. The percent biased range between +1.82 and $-6.04 \%$.

\section{Robustness to dilution}

Optimized formulation (FF1) was tested for robustness in different dilution media (distilled water, $0.1 \mathrm{M} \mathrm{HCl}$ buffer $(\mathrm{pH}$ 1.2), and phosphate buffer $(\mathrm{pH}$ 6.8)) with variable dilution fold (10, 100, and 1000 times) to resemble the 

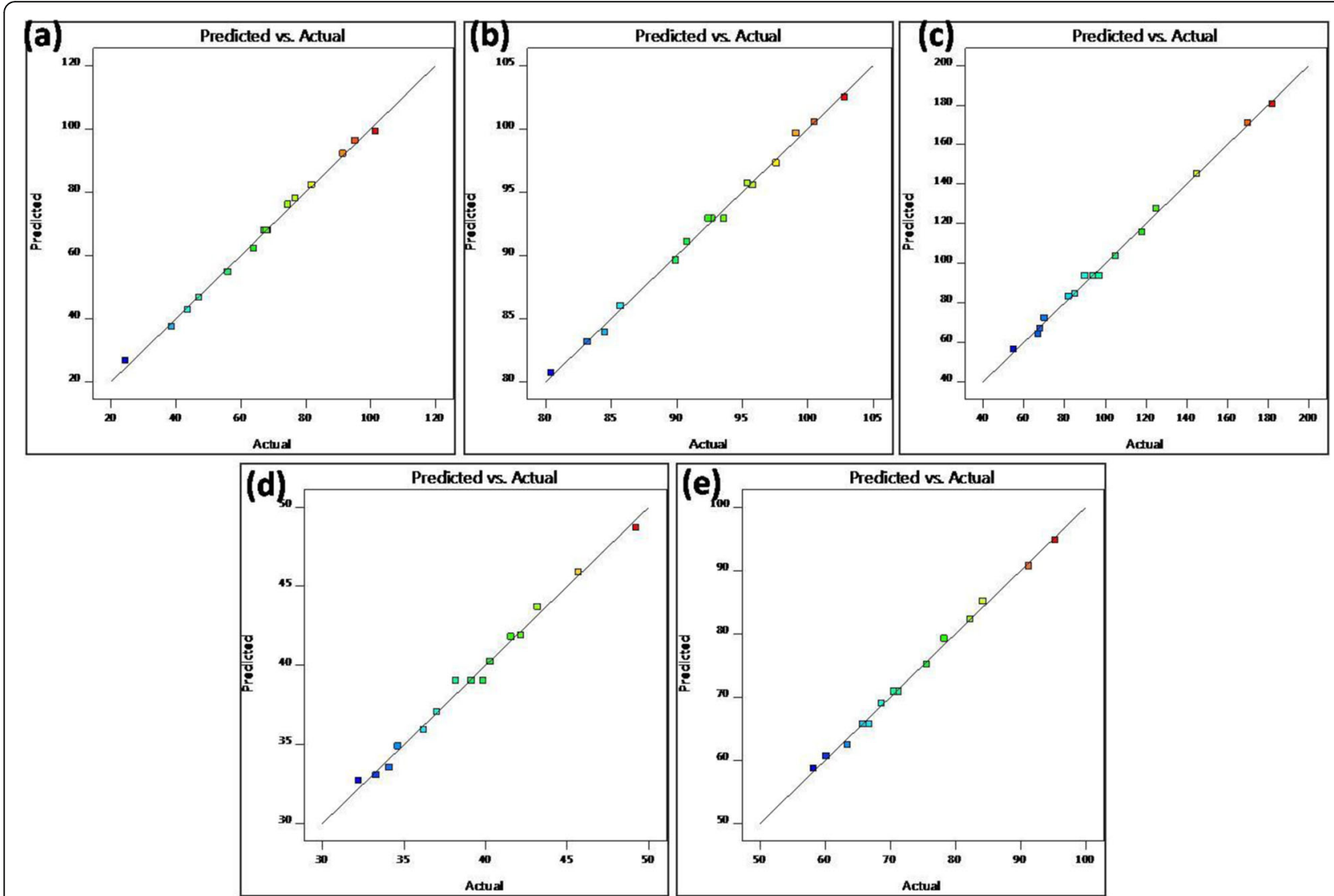

Fig. 6 Predicted vs actual plot representing the effects of $X_{1}$ and $X_{2}$ on the measured responses at the mid-level of $X_{3}$. a On globule size $\left(Y_{1}\right)$. b On \% transmittance $\left(Y_{2}\right)$. c On self-emulsification time $\left(Y_{3}\right)$. d On dissolution (\% drug release) after 5 min $\left(Y_{4}\right)$. e On dissolution (\% drug release) after $40 \min \left(Y_{5}\right)$

in vivo condition and to assure the formation of uniform emulsion. With the gradual increase in dilution and change in dilution media, there was no drug precipitation observed, even after $24 \mathrm{~h}$ of the study.

\section{Cloud point measurement}

In our study, the optimized formulation exhibited a cloud point at $63.8^{\circ} \mathrm{C}$.

\section{Transmission electron microscopy}

Figure 9 depicted the morphology of optimized formulation (FF1) which was examined using transmission electron microscope.

\section{Stability studies of optimized SNEDDS}

The optimized SNEDDS (FF1) preconcentrate and its resulting emulsion after aqueous dilution was assessed for thermodynamic stability. The result of the study showed no sign of instability (like precipitation, phase separation, creaming, etc.), neither by the preconcentrate nor by its emulsion.

\section{Discussion}

The high solubility of EZT in Peceol and Maisine was possibly ascribed to their complex composition (monoglyceride content-32-52\% and diglyceride content $(30-50 \%)$, as they belong to the class of long-chain triglycerides (LCT) containing mixed glycerides (mono and di-glycerides and free fatty acids). It is well reported in the literature that presence of mixed glycerides in formulation enhances the solvent capacity of lipid formulation. Moreover, their similarities with the lipid digestion product make them advantageous to use in the lipid formulations [33]. The high solubility of dug in the lipid phase is important for selfemulsification, as in SNEDDS drug should be present in dissolved form, providing a high concentration gradient which will serve as a driving force for the permeation of drug through GI tract [34]. Peceol was selected as oil phase for further investigations because of its high solubilization capacity for EZT. However, due to the high viscosity and gritty consistency of Maisine 35-1, it was not selected as the oil phase for the formulation development.

Selection of surfactant is important in the lipid system as they are mainly responsible for the stabilization of the emulsion. Non-ionic surfactants are safer, less irritant, and 

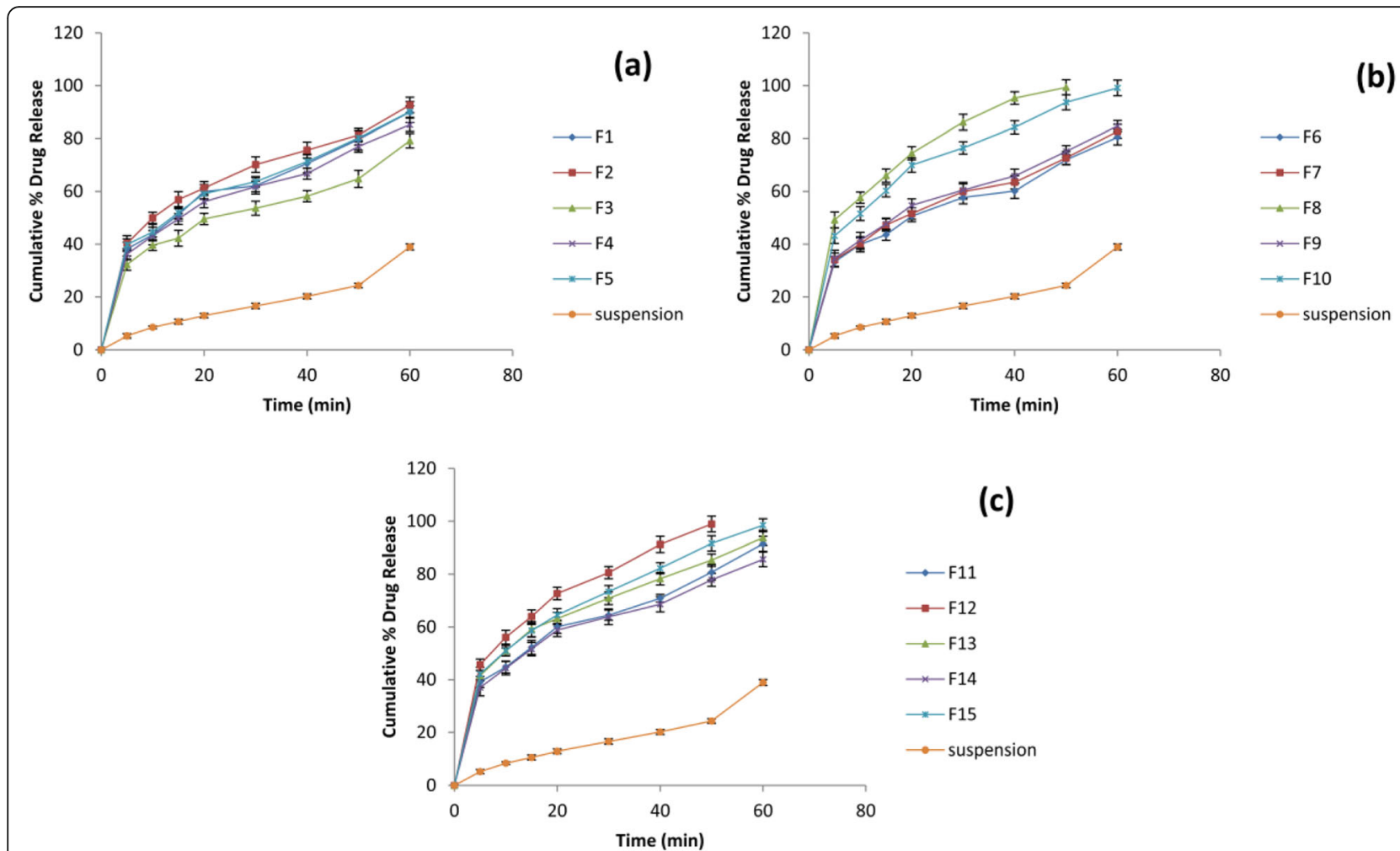

Fig. 7 Drug release profile of pure EZT-suspension and different prepared EZT-SNEDDS. (All values are mean \pm SD, $n=3$ )

exhibit greater stability of emulsion over a broad region of $\mathrm{pH}$ and ionic strength than ionic surfactants. Further, they expedite the adsorption of a drug by producing reversible alteration in the permeability of intestinal mucosa $[12,35]$. Therefore, two non-ionic surfactants (Labrasol ALF and Tween 80) were selected for the preparation of SNEEDS.

Cosurfactants are important component of SNEDDS as they help in forming and stabilizing micelles with the surfactant in the aqueous phase. In addition, they increase the drug solubility in micelles as well as prevent precipitation of drug [36]. Transcutol $\mathrm{P}$ was selected as it solubilizes maximum amount of drug.

Two batches (batches A and B) of formulations were prepared; among the batches, batch A was rejected as it resulted in the formation of a coarse emulsion. Moreover,

Table 5 Comparison of predicted and observed experimental values of optimized EZT-SNEDDS (FF1)

\begin{tabular}{llll}
\hline Response & Predicted value & Observed value & Percent bias (\%) \\
\hline$Y_{1}(\mathrm{~nm})$ & 24.72 & $26.31 \pm 2.64$ & -6.04 \\
$Y_{2}(\%)$ & 102.64 & $101.4 \pm 3.91$ & 1.22 \\
$Y_{3}(\mathrm{~s})$ & 67.99 & $69.26 \pm 2.56$ & -1.83 \\
$Y_{4}(\%)$ & 49.39 & $48.74 \pm 2.29$ & 1.33 \\
$Y_{5}(\%)$ & 97.12 & $95.38 \pm 3.67$ & 1.82 \\
\hline
\end{tabular}

*Percent bias $(\%)=($ predicted value-observed value $) /$ predicted value $\times 100$ the poor affinity of Labrasol ALF to the oil led to decreased adsorption (surface assimilation) of surfactant on to the oil globules [37], resulting in the formation of coarse emulsion and eventually phase separation.

In the phase diagram, the shaded area depicted nanoemulsification region delineating best chances or probability to form nanoemulsion while the segment surrounding this area represents biphasic formulation or formulation with poor emulsification property.

System which contains high amount of surfactant (System IV; Smix-3:1) does not show emulsification of high amount of oil. This may be ascribed to the possibility of development of liquid crystal region at high surfactant concentration, as the cosurfactant concentration is not sufficient to minimize this region [38].

The system $\mathrm{V}$ was selected to define the boundaries of the nanoemulsion as it showed the wider self nanoemulsification zone. The wider nanoemulsion region for system $\mathrm{V}$ could be due to an appropriate concentration of Smix $(3: 1.5, w / w)$. A perfect Smix can emulsify greater quantity of oil and thus the molecular structure of both surfactant (linear structure of Tween 80) and cosurfactant (shortchain amphiphilicity of Transcutol P) is responsible for the easy penetration of Transcutol P into the surfactant monolayer and form a proper arrangement with Tween 80. The hydrocarbon region of the interfacial film formed due to oil and surfactant is fluidized by the Transcutol P 


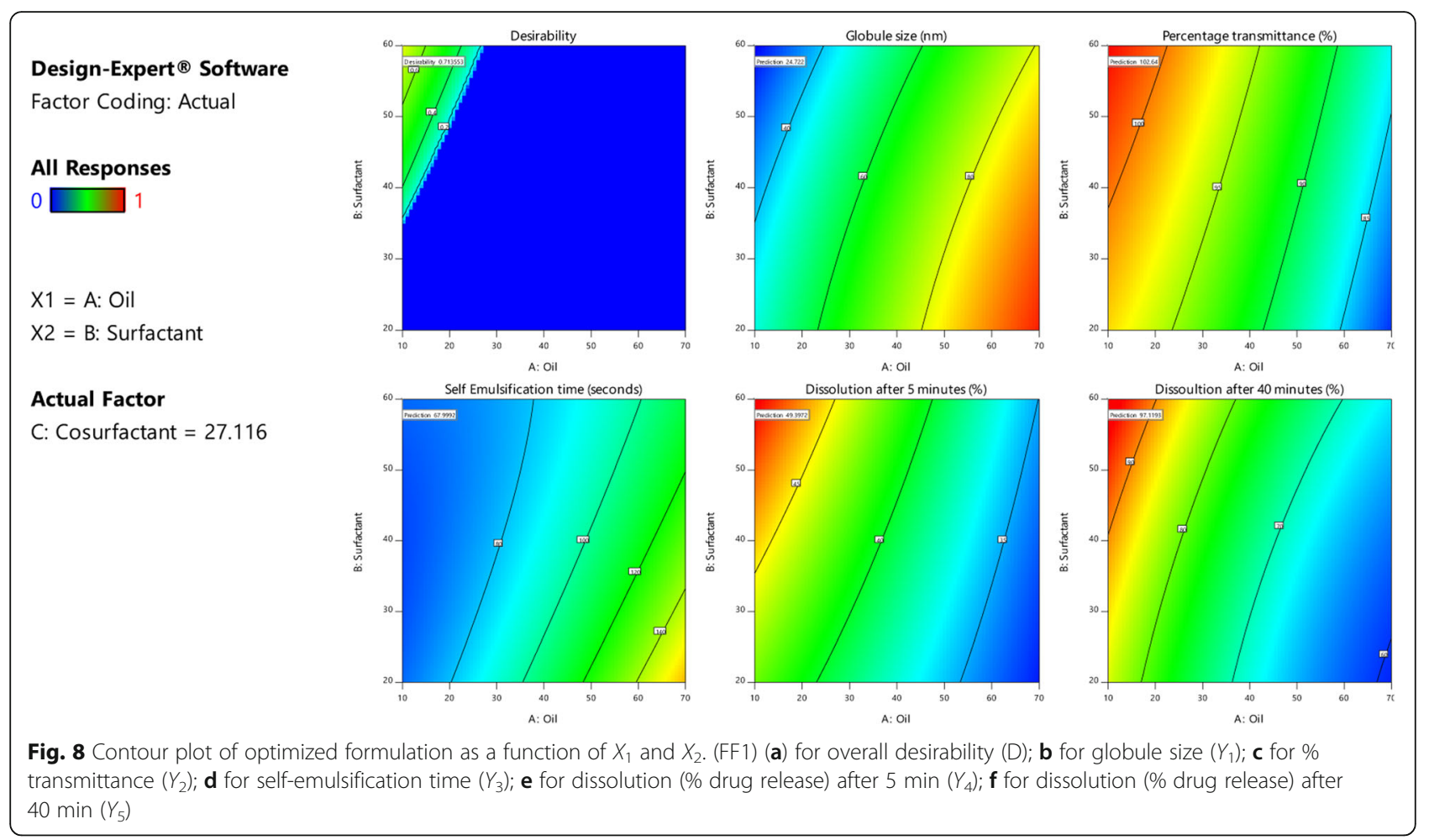

generating void space between the molecules of surfactant which ultimately results in the reduction of interfacial tension and decreased bending stress at the interface. Thus, a wider zone of nanoemulsion was observed [39].

When a complex process needs to be developed and optimized, conventional experiments require more material, efforts and thus turn out to be a tedious process. Among various experimental designs, response surface methodology (RSM) will help in overcoming these problems. This methodology is better over conventional optimization approaches because it utilizes one variable at a time (OVAT) and provides extensive information with the least number of experimentations. There are many types of response surface designs like central composite design (CCD), Box-Behnken design (BBD), Doehlert design, etc. [40].

The Box-Behnken design (BBD) is a three factor-three level design which is preferable over other because it obligates fewer experimental runs, rotatable, and it does not contain a combination of extremes (highest or lowest levels) points of the cubic region simultaneously; therefore, chances of getting unsatisfactory results are minimized [22, 41]. Therefore, BBD was selected and applied in the present investigation to comprehend the effect of three independent variables (components of SNEDDS) on dependent variables.
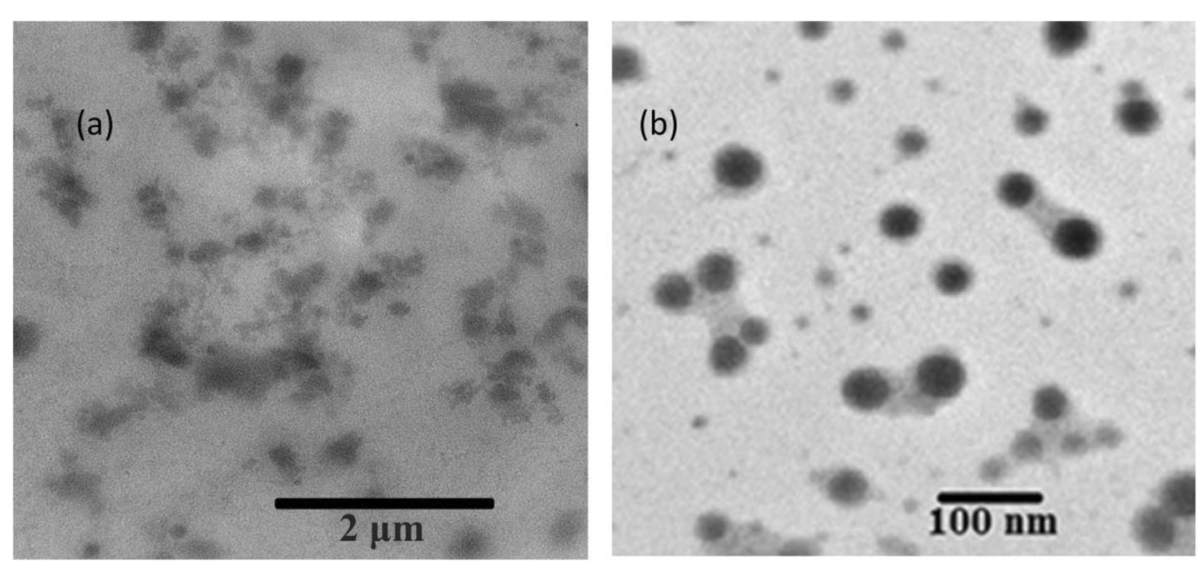

Fig. 9 TEM micrograph of optimized formulation of EZT 
As per the BBD, 15 formulations were prepared and evaluated for their response variables (globule size, percentage transmittance, self-emulsification time, dissolution after $5 \mathrm{~min}$ and dissolution after $40 \mathrm{~min}$ ). The effect of formulation composition on the response variables was also studied.

There was a clear indication from the results of globule size study that the formulation components impose a great effect on globule size. A remarkable diminution was observed with increasing concentration of surfactant and decreasing concentration of oil.

Zeta potential governs the physical stability of the emulsion. Under the electric field, the potential of a colloid particle exerted at the slipping/shear plane is termed as zeta potential [42]. As reported in various literature zeta potential values of $\pm 0-10 \mathrm{mV}$ are highly unstable, $\pm 10-20 \mathrm{mV}$ are relatively stable, $\pm 20-30 \mathrm{mV}$ are moderately stable, and above $\pm 30 \mathrm{mV}$ are highly stable system [43]. However, some colloidal systems exhibit low zeta potential but are stable, which may be assigned to the additive effect of van der Waals attractive forces and electrostatic repulsive forces of the electrical double layer (as per DLVO theory) [44]. Some steric interactions are also responsible for the colloid stability [45].

The formulations would not exhibit any coalescence as the negative zeta potential and steric effects, as the oil phase surface and mono-oleate tail of surfactant (Tween 80) exert a hydrophobic interactions which form highenergy barriers between the dispersed globules. In addition, some non-DLVO forces like high content of non-ionic surfactant and hydration of its polar head group which helps in maintaining the intrinsic stability of the system $[46,47]$. The negative charge of the free fatty acid and esters present on the oil droplets might be responsible for the observed negative zeta potential value [48].

As it was clear from the results that when the quantity of Tween 80 increased, globule size $\left(Y_{1}\right)$ decreased. This might be attributed to the localization of surfactant molecules at the interface, forming a mechanical barrier and providing a compact layer around the droplets, thereby decreasing the interfacial tension and thus prevents coalescence of oil globules [49]. The results obtained were in consonance with the study conducted by Tang et al. reporting a linear/direct relationship between surfactant and the globule size (improved emulsion stability and reduction in globule size with increasing amount of surfactant) [31].

The amount of oil also had a significant effect on $Y_{1}$. It was observed that system containing $70 \% \mathrm{w} / \mathrm{w}$ oily phase produced nanoemulsion with larger globules. This could be ascribed to the distortion of the interfacial film by the penetration of oil droplets into surfactant chain which in turn changes the surface curvature of the globule leading to an increase in size [50].
The increase in \% transmittance with decreased oil content is might be owing to the presence of more quantity of emulsifier for the emulsification process [18]. It is an index for assessing the efficiency of emulsification i.e. ability of SNEDDS to disperse properly and rapidly when exposed to dilution with water under mild agitation. This indicates the time required for the emulsification process and helps in assuring dispersion of drug in dispersed emulsion without further precipitation. The emulsification time was found to be decreased with increasing concentration of Smix.

It was clear from the model equation as well as from the model graphs that there is a relative increase in emulsification time with rise in oil content. The emulsification process tend to become slow on increasing the oil concentration, as the high oil content led to an increase in viscosity of the system which require large shear forces for dispersion $[49,51]$. Moreover, regarding effect of surfactant concentration, it was observed that there was a linear decrease in emulsification time with increase in surfactant concentration. This could be due to the more stabilization of interface with increased surfactant content. In general, the property of surfactant molecules to get adsorbs on the interface resulted into reduction in the interfacial tension. This decrease in interfacial tension depends on concentration of surfactant (Gibb's isotherm). The adsorption of surfactant on the interface helps in stabilization of emulsion either by steric stabilization or electrostatic stabilization. In the present investigation, there is a formation of o/w emulsion which was reported to be electrostatically stabilized by the repulsive forces that are generated when electrical charged surface approach other at the interface [52]. In addition, Tween 80 is composed of a $\mathrm{C} 18$ hydrophobic chain and a double bond which would give rise to a looser film and thus helps in spontaneous formation of emulsion on dilution with aqueous media [53].

Similarly, increased co-surfactant (Transcutol P) amount also decreases the emulsification time. This might be as a consequence of cosurfactant ability to lower the interfacial tension by penetrating the surfactant film, fluidizing the hydrocarbon region of the interfacial film which induces formation of void spaces between the surfactant molecules. This help in emulsification process and thus lowers the emulsification time [54].

Dissolution testing is an essential tool in predicting drug release characteristics and consistency of a formulation/product. In some cases, dissolution testing could help in estimating in vivo dissolution profile of the drug (dissolution limited systems).

The model graphs which showed effect formulation composition on dissolution after $5 \mathrm{~min}\left(Y_{4}\right)$ indicated a linear decrement in cumulative percent drug release after $5 \mathrm{~min}$ with increase in oil content. This was in agreement with 
the results of globule size and percentage transmittance. The increased oil content is responsible for increasing the viscosity of the system, which would slow down the emulsification process and thus retard the drug release [55]. The pattern was similar with results of self-emulsification time. Moreover, as discussed in the above section, the globule size of the formulations containing high oil content was large as compared to other, therefore small interfacial film area would be available for drug release.

The increasing surfactant concentration from $20 \% \mathrm{w} / \mathrm{w}$ to $60 \% \mathrm{w} / \mathrm{w}$, significantly increases the drug dissolution $(p<0.05)$. This was due to rapid formation of emulsion by the formulation when dispersed in the aqueous medium after dissolution of capsule shell. Due to self-emulsification, the free energy required is low which resulted in spontaneous formation of oil-water interface. Eventually, there is an increase in penetration of oil droplets which disrupt the interface and thereby decrease the globule size. The smaller globule size favors increase in dissolution, as large surface area is available at the interface. As mentioned in the above section, addition of cosurfactant also enhances the emulsification process and thus it also contribute in drug release $[28,56]$.

Apart from emulsification process, drug's solubility in different components of SNEDDS may also affect drug dissolution. The highest solubility of EZT was observed in cosurfactant (Transcutol P). Therefore, it might be possible that drug molecules which are solubilized in cosurfactant might dissolve more rapidly in the medium prior to emulsification [57]. This could be the reason of large amount of drug release (49.21\%) from F8 within 5 min of the study.

The effect of independent variables on response (dissolution after $40 \mathrm{~min}\left(Y_{5}\right)$ ) was similar as that observed with response $Y_{4}$. Mainly oil and surfactant content had significantly affected the drug release. As mentioned earlier, the reduction in drug release with increasing oil content is might be due to increased viscosity of the system. Although, high surfactant concentration is also associated with high viscosity and liquid crystal formation which could retard the drug release, but in this investigation drug release was found to be increased with increase in surfactant content. This could be due to two reasons: firstly, high surfactant content stabilized the emulsion by forming layer around the interface and decreasing the interfacial tension, thereby increasing the rate of emulsification and eventually drug release [58]. Secondly, the cosurfactant (Transcutol P) provides adequate flexibility to the film at the interface by decreasing the bending stress of the interface. In addition, cosurfactant like alcohol, Transcutol $\mathrm{P}$ had been shown to reduce the viscosity and help in destroying liquid crystal phase of the surfactant by distorting its chain. This loses the domain structure of the interface, thus resulting in increased mobility of both water and surfactant [59].
Desirability function is based on the conversion of all responses into a dimensionless value (desirability function). The value of desirability function ranges from 0 to 1 . The value 0 is observed when the factors give undesirable results, whereas the value 1 is attributed to optimal response for the factors under study [60]. This approach is used to produce desired robust formulation complying the maximum need of all responses within the given constraints.

After generating the polynomial equation and studying the effects of independent variables on responses, the process was optimized using desirability function. It was clearly observed and elucidated from the results that all the obtained values were in consonance with the predicted values, indicating BBD combined with desirability function as a promising approach for the optimization and evaluation of SNEDDS.

At higher dilution in vivo, there is a greater probability of drug precipitation which might significantly affect the drug absorption and its performance. Therefore, robustness to dilution was done to ensure that uniform emulsion is formed from SNEDDS [61, 62]. The results clearly suggested that the optimized formulation was robust to dilution and will maintain its performance in vivo [63].

Cloud point of an emulsion is a temperature at which the emulsion becomes cloudy, as the dissolved drug no longer remains in solution, followed by its precipitation resulting in cloudiness of emulsion [64].

The cloud point is an important parameter for assessing the stability of emulsion containing non-ionic surfactant such as Tween 80 . Chemically, Tween 80 is polyoxyethylene sorbitan monooleate and has a temperature dependent behavior. On increasing the temperature, the HLB value of surfactant changes (shifted towards lipophilicity) since the surfactant starts losing its hydrophilicity which is due to dehydration of the polyoxyethylene moiety of Tween $80[65,66]$. This results in precipitation of drug and eventually turns the clear emulsion to cloudy one. Therefore, the formulation should show cloud point above $37{ }^{\circ} \mathrm{C}$ to circumvent phase separation and phase inversion of emulsion at the physiological temperature of GIT, thereby averting drug precipitation and cloudiness [67]. The result suggested that emulsion might show highest chances of stability at normal body temperature.

The TEM micrographs showed that the nanoemulsion droplets of optimized formulation were uniform, spherical in shape and discrete.

The stability study indicates that the preconcentrate should be able to withstand the temperature variation on storage without undergoing drug precipitation and phase separation. preconcentrate and its resulting emulsion after aqueous dilution The result of the stability study revealed that the optimized formulation preconcentrate and its resulting emulsion after aqueous dilution were found to be stable and does not show instability sign. 


\section{Conclusion}

The present study demonstrates the applicability of BBD approach of RSM combined with desirability function for the designing and optimization of SNEDDS containing BCS class II drug (EZT), in an attempt to enhance the dissolution profile of the poorly soluble drug. The polynomial equations and model graphs (response surface plot and contour plots) were used for ascertaining the effects of different formulation variables (oil, surfactant and co-surfactant) on the responses (globule size, their \% transmittance, self-emulsification time, dissolution after $5 \mathrm{~min}$ and $40 \mathrm{~min}$ ). It was clear from the study that formulation variables poses a significant effect $(p<0.05)$ on the measured responses. High oil content in the formulation, resulted in formation of emulsion with large globules, decreased \% transmittance, more self-emulsification time and reduced drug release. The reverse phenomenon was observed on increasing surfactant content, which might be due to the increased stabilization and reduce interfacial tension at the interface. The drug release study showed enhanced dissolution profile of EZT incorporated in SNEDDS, as the drug release was maximum within $1 \mathrm{~h}$ of the study.

The polynomial equation and model graphs help in predicting the values of formulation ingredients for the preparation of optimized EZT-SNEDDS (FF1) with desired characteristics. The observed response values of the optimized formulation were found to be in consonance with the predicted values, suggesting effectiveness of the design model. Further, the optimized formulation showed no signs of instability. The result of this study suggested the potential of SNEDDS in improving the dissolution profile of poorly soluble drugs. Furthermore, BBD with desirability function could also be considered as a promising approach for investigating the effect of formulation variables and to optimize their values for the preparation of efficient optimized formulation. Also, the scope of this research is not confined to these studied parameters, but the performance of the system both in fasting state and fed state could also be in the area of further assessment.

\section{Supplementary information}

Supplementary information accompanies this paper at https://doi.org/10. 1186/s43094-020-00023-3.

Additional file 1. Supplementary Table 1. Percentage transmittance and visual appearance of various prepared formulation with Smix (Labrasol: Transcutol P) at 1:1 ratio. Supplementary Table 2. Percentage transmittance and visual appearance of various prepared formulation with Smix (Labrasol: Transcutol P) at 2:1 ratio.

\section{Abbreviations}

BBD: Box-Behnken design; BCS: Biopharmaceutical Classification System; EZT: Ezetimibe; PDI: Polydispersity index; SNEDDS: Self-nanoemulsifying drug delivery system

\section{Acknowledgements}

The authors express their sincere thanks to the management of IFTM University, Moradabad, Uttar Pradesh, India, for providing necessary facilities to carry out the above research work.

Authors' contributions

We declare that this work was done by the authors named in this article: PY conceived and designed the study. PY and VR carried out the laboratory work, collected and analyzed the data and drafted the manuscript. AV supervised the work and assisted in the data analysis. All authors have read and approved the final manuscript.

\section{Funding}

The authors have no funding to report.

\section{Availability of data and materials}

All necessary data generated or analyzed during this study are included in this published article. Any additional data could be available from the corresponding author upon request.

Ethics approval and consent to participate

Not applicable.

Consent for publication

Not applicable.

\section{Competing interests}

The authors declare that they have no competing interests.

Received: 21 October 2019 Accepted: 11 February 2020

Published online: 02 March 2020

References

1. Ku MS, Dulin W (2012) A biopharmaceutical classification based right-first-time formulation approach to reduce human pharmacokinetic variability and project cycle time from first-in-human to clinical proof-of concept. Pharm. Dev. Technol. 17:285-302 https://doi.org/10.3109/10837450.2010.535826

2. Amidon GL, Lennernas $H$, Shah VP, Crison JR (1995) A theoretical basis for a biopharmaceutic drug classification: The correlation of in vitro drug product dissolution and in vivo bioavailabilty. Pharm. Res. 12:413-420 https://doi. org/10.1023/A:1016212804288

3. Stegemanna S, Leveillerb F (2007) When poor solubility becomes an issue: From early stage to proof of concept. Eur. J. Pharm. Sci. 31:249-261 https:// doi.org/10.1016/j.ejps.2007.05.110

4. Blagden N, de Matas M, Gavan PT, York P (2007) Crystal engineering of active pharmaceutical ingredients to improve solubility and dissolution rates. Adv. Drug Deliv. Rev. 59:617-630 https://doi.org/10.1016/j.addr.2007.05.011

5. Karavas E, Georgarakis E, Sigalas MP, Avgoustakis K, Bikiaris D (2007) Investigation of the release mechanism of a sparingly water-soluble drug from solid dispersions in hydrophilic carriers based on physical state of drug, particle size distribution and drug-polymer interactions. Eur. J. Pharm. Biopharm 66:334-347 https://doi.org/10.1016/j.ejpb.2006.11.020

6. Brewster ME, Loftsson T (2007) Cyclodextrins as pharmaceutical solubilizers. Adv. Drug Deliv. Rev 5:645-666 https://doi.org/10.1016/j.addr.2007.05.012

7. Kesisoglou F, Panmai S, Wu Y (2007) Nanosizing-Oral formulation development and biopharmaceutical evaluation. Adv. Drug Deliv. Rev 59: 631-644 https://doi.org/10.1016/j.addr.2007.05.003

8. Serajuddin ATM (2007) Salt formation to improve drug solubility. Adv. Drug Deliv. Rev 59:603-616 https://doi.org/10.1016/j.addr.2007.05.010

9. Stella VJ, Nti-Addae KW (2007) Prodrug strategies to overcome poor water solubility. Adv. Drug Deliv. Rev 59:677-694 https://doi.org/10.1016/j.addr. 2007.05.013

10. Hauss DJ (2007) Oral lipid-based formulations. Adv. Drug Deliv. Rev. 59:667676 https://doi.org/10.1016/j.addr.2007.05.006

11. Weerapol Y, Limmatvapirat S, Nunthanid J, Sriamornsak P (2014) Selfnanoemulsifying drug delivery system of nifedipine: Impact of hydrophiliclipophilic balance and molecular structure of mixed surfactants. AAPS PharmSciTech. 15(2):456-464 https://doi.org/10.1208/s12249-014-0078-y

12. Gupta S, Kesarla R, Omri A (2013) Formulation strategies to improve the bioavailability of poorly absorbed drugs with special emphasis on self-emulsifying systems. ISRN Pharm. 2013:848043 https://doi.org/10.1155/2013/848043 
13. Udaya SM, Josephine RLF, Kiran BU (2013) Self nano emulsifying drug delivery systems for oral delivery of hydrophobic drugs. Biomed Pharmacol. J. 6(2):355-362

14. Date AA, Desai N, Dixit R, Nagarsenker M (2010) Self-nanoemulsifying drug delivery systems: formulation insights, applications and advances. Nanomedicine (Lond). 5(10):1595-1616 https://doi.org/10.2217/nnm.10.126

15. Rahman MA, Hussain A, Hussain MS, Mirza MA, lqbal Z (2013) Role of excipients in successful development of self-emulsifying/microemulsifying drug delivery system (SEDDS/SMEDDS). Drug Dev. Ind. Pharm. 39(1):1-19 https://doi.org/10.3109/03639045.2012.660949

16. Solans C, Izquierdo P, Nolla J, Azemar N, GarciaCelma MJ (2005) Nanoemulsions. Curr. Opin. Colloid. Interface Sci 10(3-4):102-110 https://doi.org/ 10.1016/j.cocis.2005.06.004

17. Lestari M, Ardiana F, Indrayanto G (2011) Ezetimibe. In: Brittain HG (ed) Profiles of drug substances, excipients and related methodology. Elsevier Inc, New York

18. Patel J, Dhingani A, Tilala J, Raval M, Sheth N (2014) Formulation and development of self-nanoemulsifying granules of olmesartan medoxomil for bioavailability enhancement. Particul. Sci. Tech 32(3):274-290 https://doi. org/10.1080/02726351.2013.855686

19. Dixit RP, Nagarsenker MS (2008) Self-nanoemulsifying granules of ezetimibe: Design, optimization and evaluation. Eur. J. Pharm. 35:183-192 https://doi. org/10.1016/j.ejps.2008.06.013

20. Craig DQM, Baker SA, Banning D, Booth SW (1995) An investigation into the mechanisms of self-emulsification using particle size analysis and low frequency dielectric spectroscopy. Int. J. Pharm 11:103-110 https://doi.org/ 10.1016/0378-5173(94)00222-Q

21. Villar ANS, Naveros BC, Campmany ANC, Trenchs MA, Rocabert CB, Bellowa LH (2012) Design and optimization of self-nanoemulsifying drug delivery systems (SNEDDS) for enhanced dissolution of gemfibrozil. Int. J. Pharm 431 161-175 https://doi.org/10.1016/j.ijpharm.2012.04.001

22. Box GEP, Behnken DW (1960) Some new three level designs for the study of quantitative variables. Technometrics. 2:455-475

23. Derringer $G$, Suich $R$ (1980) Simultaneous optimization of several response variables. J. Qual. Technol 12:214-219 https://doi.org/10.1080/00224065.1980.11980968

24. Zhang P, Liu Y, Feng N, Xu J (2008) Preparation and evaluation of selfmicroemulsifying drug delivery system of oridonin. Int. J. Pharm. 355(1-2): 269-276 https://doi.org/10.1016/j.ijpharm.2007.12.026

25. Heshmati N, Cheng X, Eisenbrand G, Fricker G (2013) Enhancement of oral bioavailability of E804 by self-nanoemulsifying drug delivery system (SNEDDS) in rats. J. Pharm. Sci. 102:3792-3799 https://doi.org/10.1002/jps.23696

26. AboulFotouh K, Allam AA, El-Badry M, El-Sayed AM (2017) Development and in vitro/in vivo performance of self-nanoemulsifying drug delivery systems loaded with candesartan cilexetil. Eur J Pharm Sci. 109:503-513 https://doi.org/10.1016/j.ejps.2017.09.001

27. Negi LM, Tariq M, Talegaonkar S (2013) Nano scale self-emulsifying oil based carrier system for improved oral bioavailability of camptothecin derivative by P-Glycoprotein modulation. Colloids. Surf. B. Biointerfaces. 111:346-353 https://doi.org/10.1016/j.colsurfb.2013.06.001

28. Parmar N, Singla N, Amin S, Kohli K (2011) Study of cosurfactant effect on nanoemulsifying area and development of lercanidipine loaded (SNEDDS) self nanoemulsifying drug delivery system. Colloids. Surf. B. Biointerfaces. 86: 327-338 https://doi.org/10.1016/j.colsurfb.2011.04.016

29. Muthukumar, M.; Mohan, D.; Rajendran, M. Optimization of mix proportions of mineral aggregates using Box Behnken design of experiments. Cement Concrete Composit. 25:751-758. https://doi.org/10. 1016/S0958-9465(02)00116-6

30. Singh SK, Verma PRP, Razdan B (2010) Glibenclamide-loaded selfnanoemulsifying drug delivery system: development and characterization. Drug Dev. Ind. Pharm. 36:933-945 https://doi.org/10.3109/ 03639040903585143

31. Tang SY, Manickam S, Wei TK, Nashiru B (2012) Formulation development and optimization of a novel Cremophore EL-based nanoemulsion using ultrasound cavitation. Ultrason. Sonochem. 19:330-345 https://doi.org/10. 1016/j.ultsonch.2011.07.001

32. Paterakis AA, Korakianiti ES, Dallas PP, Rekkas DM (2002) Evaluation and simultaneous optimization of some pellets characteristics using a 33 factorial design and the desirability function. Int. J. Pharm. 248:51-60 https://doi.org/10.1016/S0378-5173(02)00341-1

33. Savla R, Browne J, Plassat V, Wasan KM, Wasan EK (2017) Review and analysis of FDA approved drugs using lipid-based formulations. Drug Dev. Ind. Pharm. 43(11):1743-1758 https://doi.org/10.1080/03639045.2017.1342654
34. Yinghui W, Xiaoli Y, Xiaoguang S, Xuan P, Qiang B, Minchen L, Manman G, Fanzhu L (2012) Enhanced oral bioavailability of silybin by a supersaturatable self-emulsifying drug delivery system (S-SEDDS). Colloids Surf. A. 396:22-28 https://doi.org/10.1016/j.colsurfa.2011.12.025

35. Swenson ES, Milisen WB, Curatolo W (1994) Intestinal permeability enhancement: efficacy, acute local toxicity, and reversibility. Pharm. Res. 11(8):1132-1142 https://doi.org/10.1023/A:1018984731584

36. Na YG, Byeon JJ, Wang M, Huh HW, Son GH, Jeon SH, Bang KH, Kim SJ, Lee HJ, Lee HK, Cho CW (2019) Strategic approach to developing a selfmicroemulsifying drug delivery system to enhance antiplatelet activity and bioavailability of ticagrelor. Int. J. Nanomedicine. 14:1193-1212 https://doi. org/10.2147/IJN.S190426

37. Sánchez MC, Berjano M, Guerrero A, Gallegos C (2001) Emulsification rheokinetics of nonionic surfactant-stabilized oil-in-water emulsions. Langmuir. 17:5410-5416 https://doi.org/10.1021/la000723w

38. Zhu S, Hong M, Liu C, Pei Y (2009) Application of Box-Behnken design in understanding the quality of genistein self-nanoemulsified drug delivery systems and optimizing its formulation. Pharm. Dev. Technol. 14(6):642-649 https://doi.org/10.3109/10837450902882385

39. Rahman MA, lqbal Z, Hussain A (2012) Formulation optimization and in vitro characterization of sertraline loaded self-nanoemulsifying drug delivery system (SNEDDS) for oral administration. J. Pharm. Invest. 42:191-202 https://doi.org/10.1007/s40005-012-0029-0

40. Wania YB, Patil DD (2017) An experimental design approach for optimization of spectrophotometric method for estimation of cefixime trihydrate using ninhydrin as derivatizing reagent in bulk and pharmaceutical formulation. J. Saudi Chem. Soc. 21(Suppl):S101-S111 https://doi.org/10.1016/j.jscs.2013.11.001

41. Ferreira SL, Bruns RE, Ferreira HS, Matos GD, David JM, Brandão GC, da Silva EG, Portugal LA, dos Reis PS, Souza AS, dos Santos WN (2007) Box-Behnken design: An alternative for the optimization of analytical methods. Anal. Chim. Acta. 597:179-186 https://doi.org/10.1016/j.aca.2007.07.011

42. Kaszuba M, Corbett J, Watson, FM, Jones A. High-concentration zeta potential measurements using light-scattering techniques. Philos. Trans. A Math. Phys. Eng. Sci. 368:4439-4451. https://doi.org/10.1098/rsta.2010.0175

43. Patel VR, Agrawal YK (2011) Nanosuspension: An approach to enhance solubility of drugs. J. Adv. Pharm. Technol. Res. 2:81-87 https://doi.org/10. 4103/2231-4040.82950

44. Missana T, Adell A $\{2000)$ On the applicability of DLVO theory to the prediction of clay colloids stability. J. Colloid. Interface Sci. 230:150-156. https://doi.org/10.1006/jcis.2000.7003

45. Bhattacharjee S (2016) DLS and zeta potential-What they are and what they are not? J. Control. Release. 235:337-351 https:/doi.org/10.1016/j.jconrel.2016.06.017

46. Rastogi V, Yadav P, Verma A, Pandit JK (2017) Ex vivo and in vivo evaluation of microemulsion based transdermal delivery of E. coli specific T4 bacteriophage: A rationale approach to treat bacterial infection. Eur. J. Pharm. Sci. 107:168-182 https://doi.org/10.1016/j.ejps.2017.07.014

47. Rastogi V, Yadav P, Verma N, Verma A (2018) Preparation and characterization of transdermal mediated microemulsion delivery of T4 bacteriophages against E.coli bacteria: A novel anti-microbial approach. J. Pharm. Invest. 48(3):393-407 https://doi.org/10.1007/s40005-017-0335-7

48. Makadia HA, Bhatt AY, Parmar RB, Paun JS, Tank H (2013) Self-nano Emulsifying Drug Delivery System (SNEDDS): Future aspects. Asian J. Pharm. Res. 3:21-27

49. Amin MM, El Gazayerly ON, Abd El-Gawad NA, Abd El-Halim SM, El-Awdan SA (2016) Effect of formulation variables on design, in vitro evaluation of valsartan SNEDDS and estimation of its antioxidant effect in adrenalineinduced acute myocardial infarction in rats. Pharm. Dev. Technol. 21(8):909_ 920 https://doi.org/10.3109/10837450.2015.1078354

50. Shanmugam S, Baskaran R, Balakrishnan P, Thapa P, Yong CS, Yoo BK (2011) Solid self nanoemulsifying drug delivery system (S-SNEDDS) containing phosphatidylcholine for enhanced bioavailability of highly lipophilic bioactive carotenoid lutein. Eur. J. Pharm. Biopharm. 79:250-257 https://doi. org/10.1016/j.ejpb.2011.04.012

51. Nawale RB, Mehta BN (2013) Glibenclamide loaded self-microemulsifying drug delivery system (SMEDDS): Development and optimization. Int. J. Pharm. Pharm. Sci. 5:325-330

52. Urrutia PI (2006) Predicting water-in-oil emulsion coalescence from surface pressure isotherms. Dissertation, University of Calgary: Alberta (Canada).

53. Wang L, Dong J, Chen J, Eastoe J, Li X (2009) Design and optimization of a new self-nanoemulsifying drug delivery system. J. Colloid. Interface Sci. 330(2):443-448 https://doi.org/10.1016/j.jcis.2008.10.077 
54. Ahsan MA, Verma PRP, Singh SK, Samridhi YM (2014) Formulation of rosuvastatin-loaded self-nanoemulsifying drug delivery system using BoxBehnken design. Particul. Sci. Technol. 32(1):46-60 https://doi.org/10.1080/ 02726351.2013 .800929

55. Qi X, Wang L, Zhu J, Hu Z, Zhang J (2011) Self-double-emulsifying drug delivery system (SDEDDS): A new way for oral delivery of drugs with high solubility and low permeability. Int. J. Pharm. 409:245-251 https://doi.org/10. 1016/j.jpharm.2011.02.047

56. Balakrishnan P, Lee BJ, Oh DH, Kim JO, Lee YI, Kim DD, Jee JP, Lee YB, Woo JS, Yong CS, Choi HG (2009) Enhanced oral bioavailability of coenzyme Q10 by self-emulsifying drug delivery systems. Int. J. Pharm. 374:66-72 https://doi.org/10.1016/j.ijpharm.2009.03.008

57. Hu HY, Xu XL, Cong T, Wang RC, Zhang ZR (2007) Solubilities and in vitro release in microemulsions of drugs distinguished by their dissolvabilities. Chin. Pharm. J. 41:678-682

58. Kawakami K, Yoshikawa T, Moroto Y, Kanaoka E, Takahashi K, Nishihara Y, Masuda K. Microemulsion formulation for enhanced absorption of poorly soluble drugs I. Prescription design. J. Control. Release. 81:65-74. https://doi. org/10.1016/S0168-3659(02)00049-4

59. Amar-Yuli I, Wachtel E, Shalev DE, Aserin A, Garti N (2008) Low viscosity reversed hexagonal mesophases induced by hydrophilic additives. J. Phys. Chem. B. 112:3971-3982 https://doi.org/10.1021/jp711421k

60. Lee $\mathrm{DH}$, Jeong IJ (2018) A desirability function method for optimizing mean and variability of multiple responses using a posterior preference articulation approach. Qual. Reliab. Engg. Int. 34(3):360-376 https://doi.org/ 10.1002/are.2258

61. Balakumar K, Raghavan CV, Selvan NT, Prasad RH, Abdu S (2013) Self nanoemulsifying drug delivery system (SNEDDS) of rosuvastatin calcium: Design, formulation, bioavailability and pharmacokinetic evaluation. Colloids Surf. B. Biointerfaces. 112:337-343 https://doi.org/10.1016/j.colsurfb.2013.08.025

62. Elnaggar YSR, El-Massik MA, Abdallah OY (2009) Self-nanoemulsifying drug delivery systems of tamoxifen citrate: Design and optimization. Int. J. Pharm. 380:133-141 https://doi.org/10.1016/j.ijpharm.2009.07.015

63. Khan AW, Kotta S, Ansari SH, Sharma RK, Ali J (2015) Self-nanoemulsifying drug delivery system (SNEDDS) of the poorly water-soluble grapefruit flavonoid Naringenin: Design, characterization, in vitro and in vivo evaluation. Drug Deliv. 22(4):552-561 https://doi.org/10.3109/10717544.2013.878003

64. Singh D (2011) Effect of different additives on cloud point of non ionic surfactant. Dissertation, National Institute of Technology: Rourkela (Odisha), India.

65. Prieto C, Calvo L (2013) Performance of the biocompatible surfactant tween 80 , for the formation of microemulsions suitable for new pharmaceutical processing. J. Applied Chem. 2013:ArticleID 930356. https://doi.org/10.1155/ 2013/930356

66. Florence AT, Madsen F Puisieux F (1975) Emulsion stabilization by non-ionic surfactants: the relevance of surfactant cloud point. J. Pharmacy Pharmacol. 27(6):385-394. https://doi.org/10.1111/j.2042-7158.1975.tb09466.x

67. Subramanian N, Sharavanan SP, Chandrasekar P, Balakumar A, Moulik SP (2016) Lacidipine self-nanoemulsifying drug delivery system for the enhancement of oral bioavailability. Arch. Pharm. Res 39(4):481-491 https://doi.org/10.1007/s12272-015-0657-9

\section{Publisher's Note}

Springer Nature remains neutral with regard to jurisdictional claims in published maps and institutional affiliations.

\section{Submit your manuscript to a SpringerOpen ${ }^{\circ}$ journal and benefit from:}

- Convenient online submission

- Rigorous peer review

- Open access: articles freely available online

- High visibility within the field

- Retaining the copyright to your article

Submit your next manuscript at $\boldsymbol{\nabla}$ springeropen.com 